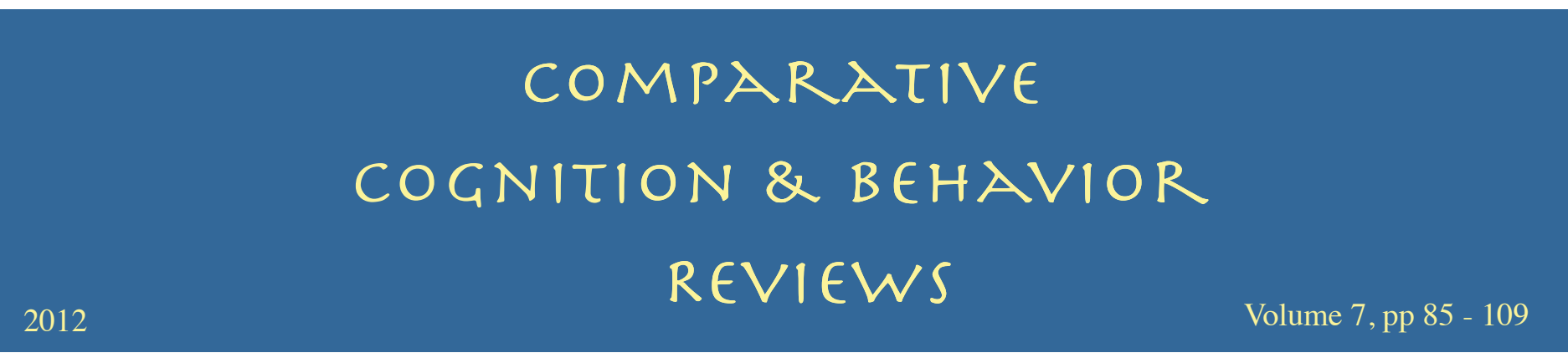

\title{
Information Seeking in Animals: Metacognition?
}

\author{
William A. Roberts, Neil McMillan, Evanya Musolino, and Mark Cole \\ University of Western Ontario
}

\begin{abstract}
Metacognition refers to humans' ability to monitor the state of their own learning and to judge the correctness of information retrieved from memory. Inferences about metacognition-like processes in non-human animals have been made from studies in which subjects judge the adequacy of previously presented information and from information seeking studies in which no prior knowledge exists. This article briefly reviews the former type of experiments but focuses on studies of information seeking. A number of studies now indicate that apes and monkeys will look down opaque tubes or under opaque containers to see the location of a hidden reward. They less often make looking responses when other information indicates the location of reward, such as visible baiting, transparent tubes or containers, or logical inference. Studies of information seeking in pigeons, rats, and dogs are reported that indicate they do not readily show the types of looking responses seen in primates. If given a forced choice between stimuli that do and do not yield information about the location of reward, however, these non-primates make the informative choice. It is suggested that the choice of information in these pigeon, rat, and dog experiments may be a form of secondary sign-tracking and thus different from the metacognition-like processes used by primates.
\end{abstract}

Keywords: comparative cognition; information seeking; metacognition; observing response; sign tracking

A suite of processes now fall into the category of human self-reflective consciousness. These include self-awareness, theory of mind, mental time travel, and metacognition. Each of these involves an individual remembering or inferring the contents of his/her own mind or that of another person. Although these processes have often been isolated for study, they undoubtedly overlap and interact with one another in daily cognitive activity. Self-awareness makes a person aware of his/her own body and mind as separate from other people, with private thoughts, intentions and motivations. Theory of mind is defined as awareness that others also have a private mind that contains information and intentions which may be inferred (correctly or incorrectly) from another's behavior. Mental time travel refers to the human

\footnotetext{
Support for research reported in this article was provided by a Discovery Grant from the Natural Sciences and Engineering Research Council of Canada to William A. Roberts.

Contact information: William A. Roberts, Department of Psychology, University of Western Ontario, London, Ontario N6A 5C2 Canada Phone:(519) 661-2111 Ext. 84686

Email: roberts@uwo.ca
}

ability to project ourselves mentally through time. Memory for specific past episodes is referred to as episodic memory (Tulving, 1972, 1985), and cognitions about future events involve anticipation or future planning (Atance \& O'Neil, 2001). Metacognition is closely related to self-awareness, as it is one's ability to assess the contents of his/her own mind. Knowing whether or not we can gain access to particular information allows us to take appropriate action when performing tasks that require this information.

Although it is generally agreed that adult humans have all these processes, a flurry of developmental studies have been carried out to examine their properties in children and the ages at which they appear (Terrace \& Metcalfe, 2005). In addition, research in the field of animal cognition has examined the possibility that such processes or their precursors might be found in nonhuman species. Thus, claims of evidence for each process have been reported from animal research, much of it from studies of nonhuman primates (apes and monkeys), but with some important reports of evidence from nonprimate mammals and birds. Controversy abounds surrounding these reports of animals showing self- 
awareness (Heyes, 1994, 1995), theory of mind (Povinelli, have been taken in animal studies (Kornell, 2009; Kornell, 2000), mental time travel (Suddendorf \& Corballis, 2007; Son, \& Terrace, 2007; Middlebrooks \& Sommer, 2011; SutZentall, Singer, \& Stagner, 2008) and metacognition (Crys- ton \& Shettleworth, 2008; Terrace \& Son, 2009).

tal \& Foote, 2009, 2011; Jozefowiez, Staddon, \& Cerutti 2009)

The second paradigm does not involve the presentation of initial information to be judged as sufficient for a correct

The term metacognition usually refers to humans' ability to make judgments about their own knowledge. These judgments are based on monitoring processes, such as judging whether one has learned about a particular topic and how much has been learned, feelings of knowing judgments about memory, and confidence judgments about the correctness of memories that have been retrieved. Such judgments then give rise to cognitive control processes such as selection of type of processing to be performed, how much study time will be given to different materials, selection of rtrieval search strategy, and finally termintion of son of (Mevalion of search Tetcalfe, 2009; Nelon, The functional value of metacognitive processes is that they
often allow people to form superior strategies for learning often allow people to form superior strategies for learning
and retrieval of information. Thus, people may choose to and retrieval of information. Thus, people may choose to known than to material they judge to be well known (Son \& Metcalfe, 2000).

In this article, we focus on the question of metacognition in nonhuman animals (hereafter called animals). Two types of paradigm have emerged for the study of metacognition in animals. The first involves tasks in which an animal is
provided with a piece of information that will allow it to choose a correct response and obtain a reward. That piece of information may be degraded, however, in several ways. It may be difficult to discriminate which response it indicates, or, in the case of memory for a sample stimulus, the memory may be weak or degraded by the passage of a retention interval. The critical manipulation involved in this paradigm is the provision of an alternate response to that of immediately taking the test (choosing the correct or incorrect response). The alternate response is often called an "escape" or "uncertainty" response and allows the subject to go to a new trial (ainty" response and allows the subject to go to a new trial (with a nominal reward less than that given for the correct esponse). The question addressed by these procedures is whether an animal will choose to take the test when condi-
tions favor greater knowledge of the correct response and to avoid the test when conditions favor less knowledge of the avoid the test when
correct response.

In an additional variation on judgment about the cognitive state of information, subjects may make a judgment about a stimulus or take a memory test and then be asked to give a confidence rating or bet about how certain they are of the correctness of their response. Confidence ratings correlate positively with accuracy of judgment or recall in human
studies (Shimamura \& Squire, 1988), and similar judgments response but instead asks what an animal will do when it has no information about the correct response on a particula trial. A request of a human for information which he or she does not possess usually leads to a search for that information in a reference source. In comparative studies, the question of interest is whether an animal given no informatio about the response necessary for reward will take appropriate action to obtain that information or will respond withou the information. We will briefly review experiments that require animals to judge the likelihood of a correct response the article will concern recent studies of the second par digm. Experiments designed to find out if animals will seek ut needed information to respond correctly will be considered for primates, pigeons, rats, dogs, and insects.

\section{What Does It Mean to Attribute} Metacognition to Animals?

Before reviewing research on uncertainty monitoring and information seeking in animals, some comment should be made about the psychological and philosophical basis fo attributing metacognition to animals. As is the case with the other processes discussed in the opening to this article metacognition is a form of self-reflective cognition in people. Humans can verbalize the mental experience of being certain or uncertain of a memory or a psychophysical judgment. Verbal judgments of confidence or knowing correlate highly with accuracy of psychophysical response and recall. Animals of course do not have human language and thus we have no direct window on the basis for their judgments. This limitation combined with the obviously greate abstract cognitive abilities of humans has often led to conavims. The applitive abilities in ist to In the case of metacognition, two levels of cognition seen the immedate information available, perhaps the degree of similarity of two stimuli to be compared or the strength of a memory trace. Beyond this initial evaluative level, a meta level of cognition then must evaluate the extent to which the primary level information is sufficient for overt judgment or recall. The distinction between these levels has sometimes been referred to as first-order and second-order (Carruthers, sociative models have been advanced to suggest that only given information with which they are provided. Most of troversy regarding the interpretation of cognitive abilites in In the case of 2008), lower-level and higher-level (Smith et al., 2008), or public and private information (Hampton, 2009a). As- cuing at the first-order or public information level may be necessary to explain metacognition phenomena found with animals (Crystal \& Foote, 2009, 2011). Smith et al. (2008) have argued to the contrary that it should not be surprising to find metacognitive evaluation in animals (at least primates and dolphins) confronted with difficult decisions. Further, Hampton (2009b) has suggested that labeling metacognition as a higher process, as opposed to processing of immediate stimuli as a lower process, may be imposing unnecessarily stimuli as a lower process, may be imposing unnecessarily complex human value judgments on a basic process. Thus, an animal's brain might be wired to make uncertainty judgments without internal awareness of this process. Beran and Smith (2011) suggest "...the capacity for information seeking or for elemental forms of metacognitive monitoring do not necessarily imply full conscious awareness or full selfawareness as animals manage adaptively the flow of information within our tasks.” (p. 103).

One solution to this controversy may be to adopt the language used to describe retrospective mental time travel or episodic memory in animals. Clayton and Dickinson (1998 1999) found evidence suggesting that scrub-jays could remember the what, where, and when properties of specific previous events. These properties met the initial criteria for episodic memory in humans suggested by Tulving (1972) but not the criterion of autonoetic consciousness later added by Tulving (1985). Because consciousness cannot be accessed in a scrub-jay (or other animals showing what-where-when memory), Clayton and Dickinson (1998) labeled their finding "episodic-like memory", meaning that it met all of the behavioral criteria for episodic memory. Thus, observations with animals that meet the behavioral criteria of metacognition might be called "metacognition-like" to distinguish nition might be called "metacognition-like" to distinguish them from human metacognitive phenomena that include introspective reports of feelings of knowing and degree of certainty versus uncertainty. It is not clear whether the term metacognition-like has theoretical value or is simply a semantic dodge. In any case, the position we take here is that the study of metacognition-like effects in animals is important because it both yields new behavioral cognition experiments and phenomena with animals and raises interesting theoretical questions.

Judging the Adequacy of Current Knowledge

Experiments reported during the past 15 years have led to the suggestion that metacognition may be found in nonhuman primates (Hampton, 2001; Hampton, Zivin, \& Murray, 2004; Kornell et al., 2007; Smith, Shields, Allendoerfer, \& Washburn, 1998; Smith, Shields, Schull, \& Washburn, 1997 Smith, Shields, \& Washburn, 2003) and in a bottlenosed dolphin (Smith, Schull, Strote, McGee, Egnor, \& Erb, 1995). These experiments generally require the subject either to make a psychophysical response or to take a memory test
As an example of a psychophysical experiment, Shields, Smith, and Washburn (1997) trained rhesus monkeys to make same-different judgments between boxes containing pixel densities. Monkeys used a joystick to move a cursor the boxes (same judgment), to a letter D (different judgor different judgment led to reward, and an incorrect same or different judgment led to no reward and timeout. Choice of the star cancelled the trial and led to the next trial after a imeout. Overuse of the star response caused the timeout to increase progressively. After training with pixel densities

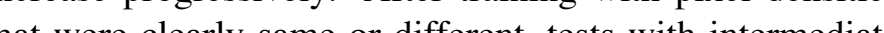

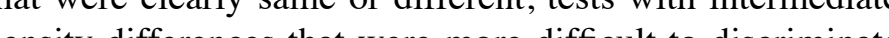
ed to increased feeluency of choice of the str und esponse over the frequency of its choice at the more treme same or different ends of the similaity dhe more ex-

In a memory experiment, Hampton (2001) showed two rhesus monkeys a single image on a screen at the beginning of a trial. After the image disappeared and a delay interval elapsed, monkeys were forced to take a memory tes on one third of the trials; matching and nonmatching images appeared, and only choice of the matching stimulus yielded reinforcement. On the other two thirds of the trials, stimuli appeared that symbolized escape or the memory test. Choice of the memory test stimulus led to the same choice between matching and nonmatching images given on forced test trials. Choice of the escape stimulus, however, terminated the trial and led to the next trial. Importantly, choice of the escape stimulus led to delivery of a modest reward (a standard reward pellet), but choice of the matching stimulus in the memory test yielded a preferred peanut reward. Choice of the nonmatching stimulus in the memory est yielded no reward. This experiment produced three important fings. Fist, monkeys showed better memory for ench per to take ke the ny test han the fing because perfort on for sent the average of trials on which memory was good and poor, whereas performance on chosen memory tests should represent only trials when the monkey judged memory to be good. Secondly, as the retention interval between sample and test increased from 12.5 to 200 seconds, the level of overall matching declined (forgetting) and the frequency of choice of the escape stimulus increased markedly. Finally, as the retention interval increased, the difference in correct matches between chosen and forced memory test trials became larger. Thus, as memory weakened with longer retention intervals, a greater proportion of forced tests, but not chosen tests, would be based on poor memory. The findings were clearly in line with the poor memory. The finding chose to take the wih the theoretical idea that monkeys 
correct match but chose to escape the trial when their memory was weaker and they felt uncertain of the correct match.

In a more recent study, Suda-King (2008) tested six orangutans on a task in which the apes chose between two blue opaque cups, with two grapes placed under only one of the cups. Subjects were tested on visible trials when they could see the correct cup baited and hidden trials on which they could not see which cup was baited. On both types of trials, an additional yellow cup was available which yielded one grape if chosen and acted as an escape response from the trial. Orangutans showed a clearly higher preference fo the escape response on hidden trials than on visible trits. the escape response on hidden trials than on visible trials. In another experiment, the positions of the blue cups were switched on some trials by rotating them clockwise before choice. This visible displacement of the cup containin reward was intended to create some confusion in memory about reward location. Subjects chose the escape alternative
more often on switched trials than on non-switched trials.

In a study with two capuchin monkeys, Fujita (2009) had subjects choose among nine comparison stimuli the one that matched a previously seen sample stimulus. On different trials, subjects were forced to take the memory test, forced to press an escape icon that led to the next trial, or were given a choice between taking the memory test or escaping. On choice trials when the retention interval was increased from 2 to 16 seconds, one monkey showed increasingly better matching performance on chosen trials over forced trials and increasing use of the escape alternative at the longer delays. This monkey also showed more frequent choice of the escape icon on test trials on which no sample was shown than on memory tests on which a sample had been presented.

Theoretical controversy has arisen recently concerning the use of an uncertainty response as a measure of the state of an animal's knowledge (Crystal \& Foote, 2009, 2011; Jozefowiez et al., 2009; Smith et al., 2008). Smith et al. (2008) have advanced an associative model of metacognition experiments that involves training with stimuli at the ends of a stimulus dimension and tests at the middle of the dimension. Based on this training, response strength should be high for the training stimuli but drop to a low level for intermediate stimuli as a conseque of stimulus gerer for intermediate stim. decrement. Because the uncertainty response is periodically reinforced, it has a low level of response strength that will exceed a theshold value and the generalized level of response strength for the trained responses at the middle of the stimulus dimension. They ran a large number of computer simulated trials and found both greatest preference for the uncertainty response at intermediate points on the stimulu dimension and better performance on chosen trials than on forced trials. Crystal and Foote $(2009,2011)$ have extended this model to delayed matching experiments by arguing that memory strength is high immediately after a sample stimuus will lead to choice of a memory test. As the retention interval increases, however, memory strength will decay to a point below the threshold for choice of the memory test. Because the escape response is periodically reinforced, its strength will exceed that of the memory est response at long retention intervals, and subjects will choose to escape.

However, there is also evidence that challenges an associative account of uncertainty responding in primates. For example, Kornell et al. (2007) trained rhesus monkeys to make confidence judgments about prior choices. In an initial task, monkeys learned to choose the largest or smalles circle shown among a set of nine circles on a screen. After choosing a circle, a monkey was given a choice between two

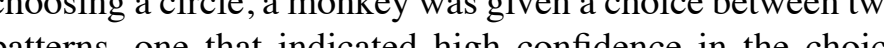
pand phe of the (later traded for food reward) if the initiard of three tokens (later trated for food reward) if the in whal circle chosen was correct and loss of three tokens if the initial circle chose was incorrect. Choice of the low confidence alternative le was incorrect and loss of three tokens if the circle chosen was correct. As a transfe test, monkeys then were trained to perform a memory task in which they were initially shown a list of six pictures an hen had to choose the comparison stimulus that matched an item from the list. When given the confidence judgment tes immediately after choosing a comparison picture, monkeys showed immediate transfer by choosing the high confidence symbol more often after correct matches and the low confidence symbol more often after incorrect matches. Rhesus monkeys have also shown immediate transfer of uncers judgments between different psychophysical tasks (Couchman, Coutinho, Beran, \& Smith, 2010)

Smith et al. (2008) argued that associative accounts of uncertainty responding fail to explain why monkeys transferred the uncertainty respone accurately to novel simi and tasks (Courman et al. 2010; Kornell et al 2007; Wall et al., 2007; Why monkeys conWhe uncertainty response when its use was no (Couchma ent Further, monkeys do not always make the uncertainty response under stimulus conditions that the associative mode suggests they should (Beran, Smith, Coutinho, Couchman, \& Boomer, 2009; Smith, Beran, Couchman, Coutinho, \& Boomer, 2009) and do make the uncertainty response to difficult discriminations that involve only abstract relationa comparisons (Smith et al., 2003).

Although most of the animal research on memory uncertainty judgments has been done with monkeys, some work has appeared with pigeons and rats. Inman and Shettleworth (1999) used a delayed matching-to-sample procedure. After seeing a sample stimulus and enduring a delay, pigeons were presented with a matching image, two nonmatching distracters, and an escape response symbol. Choice of the matching stimulus led to six reward pellets, and choice of a nonmatching stimulus led to no reward; choice of the escape stimulus led to delivery of three pellets and the intertrial interval. On memory-only trials, only the matching and nonmatching On memory-only trials, only the thing and nonmatching stimuli were shown. Some of the pigeons showed highe matching accuracy on chosen memory-test trials than on forced memory-test trials, but this effect did not increase as the retention interval was made longer. Inman and Shettleworth performed an additional experiment in which pigeons chose to escape or to take the memory test before matching and nonmatching stimuli were shown, as in the Hampton (2001) procedure. None of the pigeons tested showed clearly better performance on chosen over forced memory-tes trials (See Sole, Shettleworth, \& Bennett, 2003, for similar pigeon results from a perceptual judgment task). Sutton and Shettleworth (2008) revisited the problem of metacognition in pigeons in a further set of experiments that included one in which pigeons made confidence judgments after taking the memory test. Although individual pigeons occasionally showed a pattern of results suggestive of metamemory, the overall findings again failed to yield support for metamen ry in pigeons.

Evidence more favorable to the possibility that pigeons might show the signature effects found with monkeys has recently been reported by Adams and Santi (2011). After viewing a short 2-second or a long 8-second duration of a feeder light as a sample stimulus, pigeons chose between ide keys containing vertical or horizontal stripes. Peckside keys conting vertical or hizontal stipes. Peck ing one stripe pattern led to a mory ted red and green comparison stimuli were presented with a peck on one color leading to 8 seconds of reinforcement after a short sample and a peck to the o her color leang to 8 seconds of reinforcement after a long sample. Pecking the other stripe pattern was an escape response that yielded 4 seconds of reinforcement and led to the intertrial interval with no presentation of the comparison stimuli. Pigeons were given forced memory tests intermixed with probe trials on which they chose between the memory test and escape. Although the overall level of escape was fairly high ( $55 \%$ of choice trials) matching accuracy did not differ between forced and chosen memory tests. As the pigeons were given further training and testing, however, interesting differences emerged. Birds now showed overall higher matching accuracy on chosen tests than on forced tests. To increase the difficulty of the memory tests, the retention interval was increased from 0 to 10 seconds. Two pigeons showed a clear increase in es 0 to responses at the 10-second retention interval compared to
0 -second interval. However, these pigeons did not show a greater difference in matching accuracy between forced and chosen tests at the longer retention interval than at the shorter retention interval. Matching accuracy at the long reention interval was near chance under all conditions, perhaps because pigeons had totally lost the memory trace over 10 -second delay.

In experiments similar to the Kornell et al. (2007) monkey studies, Nakamura, Wath had six pigeons and three bantams make bets or confidence judgments after taking a delayed matching-to-sample memory test. After choice among four comparison stimuli, one of which matched a previously seen sample stimulus, pigeons chose between icons that represented safe and risk reponses. The safe response ended the trial with a low probability of reward (33\%); choice of the risk response led to inf to no rect. Eight of the nine birds tested chose the safe icon inore requenty on tials when their mathing response wa correct than the was inexperiments indicated that some of the birds transferred this behavior to delayed matching tests with new stimuli.

One study with rats did report findings suggestive of metacognition (Foote \& Crystal, 2007). Rats were trained to press one lever after hearing white noise played for shor intervals and another lever after hearing white noise played or long intervals. They were then tested with samples that included several noise durations of intermediate length. Some duration-discrimination tests were forced, but other ests included a choice between two nose-poke responses, one of which led to insertion of the levers into the chamber for the test, and the other of which allowed the rat to escape from the trial. Rats chose to escape from trials more often at the difficult intermediate noise durations and performed better on chosen tests than on forced tests. It should be noted that only three out of eight rats trained learned to decline the duration test, and the data that appered to support metacognition were obtined from just these three rats. Moreover, Crystal and Foote $(2009,2011)$ bave recently argued that the results are better explained by the associative model already described.

\section{Studies of Observing Response}

Before reviewing recent research on information seeking in animals, some mention should be made of earlier experiments carried out in animal learning laboratories concerned with observing responses (Bower, McLean, \& Meacham, 1966; Hendry, 1969; Kelleher, 1958; Kendall, 1965, 1974; 1966; Hendry, 1969; Kelleher, 1958; Kendall, 1965, 1974;
Prokasy, 1956; Wycoff, 1952). In these experiments, animals were typically trained in an apparatus in which re- 
sponding led to more and less preferred outcomes: food It was found that 13/16 pigeons preferred to peck the sideversus no-food or a lower versus a higher fixed-interval or key that led to red and green cues and $50 \%$ reinforcement. fixed-ratio schedule of reinforcement. These outcomes var- Thus, pigeons preferred to observe red and green cues that ied randomly between trials, but within trials animals could signaled certain reinforcement only $50 \%$ of the time ove make an observing response that would indicate the nature blue and yellow keys that signaled uncertain reinforcemen of the upcoming outcome. For example, Wycoff trained pi- but yielded reinforcement $75 \%$ of the time. Although sevgeons to peck a white key for 1 minute that would termi- eral theories may be invoked to account for this effect, it is a nate in reinforcement or no reinforcement. By pressing treadle, the pigeon could change the key color from white to red indicating a reinforced trial or to green indicating a to reinforced trial. In a T-maze experiment, Prokasy reinfoncinoiced choices of each side of the maze on $50 \%$ of the trials. Delay chambers on each side of the maze were black on some trials and white on others. On one side of the maze, the brightness of the delay chamber was correlated with reinforcement or non-reinforcement in the goal box, and, on the other side of the maze, the brightness of the delay chamber was uncorrelated with the contents of the goal box. Pigeons in the Wycoff experiment regularly pressed the treadle, and rats in the Prokasy experiment preferred the side of the maze leading to the delay box containing correlated cues. Accounts of observing responses in these experiments ranged from a preference for information to the possibility that anticipation of a reinforcer allowed an animal to prepare in some way to consume it. An explanation favored by many was that animals received more secondary reinforcement from choosing an observing response than from choosing its alternative (Dinsmoor, 1983; Mackintosh, 1974; Roper \& Zentall, 1999). In (he Proksy experiment, for , Roper \& Zentall, 1999). In the Prokasy experive cue was always associated with reinforcement and the other was never associated with reinforce of the noninformative black and white delay boxes, each was equally often associated with reinforcement and non-reinforcement If the consistently reinforced cue had stronger secondary reinforcing strength than that of the combined inconsistently reinforced non-informative cues, choice of the observing response could be explained by its receiving more secondary reinforcement than the alternative response (Dinsmoor, 1983).

Even more striking is a recent report by Gipson, Alessandri, Miller, and Zentall (2009; Experiment 2; also see Zentall, 2011). Pigeons chose between left and right white keys, with pecks on one key turning the key red on a random $50 \%$ of the trials and green on the other $50 \%$ of the trials. When the key turned red, it signaled a fixed-interval 30 -second schedule with $100 \%$ reinforcement, but, when the key turned green, it signaled $0 \%$ reinforcement. Thus, the overall payoff for choosing this key was 50\% reinforcement. Pecks on the other sidekey turned it blue on a random 50\% of the trials and yellow on the other $50 \%$ of the trials. Both the blue and yellow keys signaled a fixed-interval 30-sect schedule that ended in reinforcement on $75 \%$ of the trials.

In a ground-breaking set of studies, Call and Carpenter (2001) tested apes (chimpanzees and orangutans) an 2.5-year-old children on two- and three-tube tasks. Rectsubject. On some trials, the subject could see in which tube for children), but on other trials the baiting procedure was hidden from the subject's view. Of critical importance, the subject could bend down and peer through the hollow tubes. The ape or child then made its choice by touching one tube, and the experimer re the rect tube had been chosen. The major finding reported with both apes and children was that hey were much more likely was baited (and successfully retrieve the reward) then tube hey had (and successtully retrieve the reward) than when

Before the experimental tests, the subjects were allowed to explore the tubes by touching them and looking through them for no more than 5 minutes. It could be argued that the apes carried over a looking response from this brief iniimmediacy of the looking response, instead of other exploratory responses such as poking at them, suggests they understood the functional value of looking down the tubes. In Experiment 1 with three chimpanzees and three orangutans, al the tubes on the first unseen trial; the remaining chimpanzee looked through the tubes on the third unseen trial. In Experiment 2, eight out of eleven chimpanzees tested looked into the tubes on unseen trials. Of these eight chimpanzees, fou looked into the tubes on the first unseen trial, one looked on the second unseen trial, another on the sixth unseen trial, and the remaining two on Trials 17 and 25 .

It could be argued of course that the apes had an innate predisposition to explore and look down tubes that would have occurred without prior experience with the tubes. A more recent finding reported by Call (2010) speaks to this argument that apes simply made a visual exploratory response when they could not see food (Crystal \& Foote, 2009, 2011). The study used gorillas, chimpanzees, and bonobos that had previously shown the ability to use the noise mos that had previously show the abily to use the noise made by hidden baiting of one of two opaque tubes, the experimenter picked up each tube, shook it, and returned it to its original position before the subject chose between the tubes. Shakposition before the subject chose between the tubes. Shaking the baited tube made an audible rattling sound. Apes that chose the correct tube on most of the trials first looked down the tubes significantly less often when the tubes were shaken than when the tubes were not shaken. The presence of an alternative auditory cue clearly reduced the tendency to use visual searching.

Another finding of interest reported by Call and Carpenter

2001) was that apes appeared to infer the contents of an opaque tube without looking through it. Given two tubes to choose from on an unseen trial, an ape that first looked down empty tube then chose the remaining tube without looking in it.

The finding that a number of apes immediately looked down the tubes on trials when they had not seen which tube was baited indicates that they performed a purposeful beperior that served to provide important information. The performance of this additional looking behavior before makng a choice further suggests that these primates understood or had insight into the nature of tubes and how the location of food could be revealed by looking through them. The metacognition aspect of these experiments arises from the finding that apes looked down tubes more frequently when they had neen them baited then when they had seen then formation seeking was most likely to occur in the absence of knowledge about reward location.

Hampton et al. (2004) adapted the Call and Carpenter 2001) paradigm for the study of rhesus monkeys. Monkeys were trained with four tubes, one of which contained a food reward. To obtain the reward, a monkey had to grasp and aise the correct tube into an upright position, allowing the reward to fall out where it could be taken and consumed (See Figure 1). Monkeys initially were trained to pull on transangular opaque tubes were placed horizontally in front of a the experimenter placed a reward (food for apes and stickers tial contact with tubes to the testing situation. However, the three orangutans and two of the chimpanzees looked through

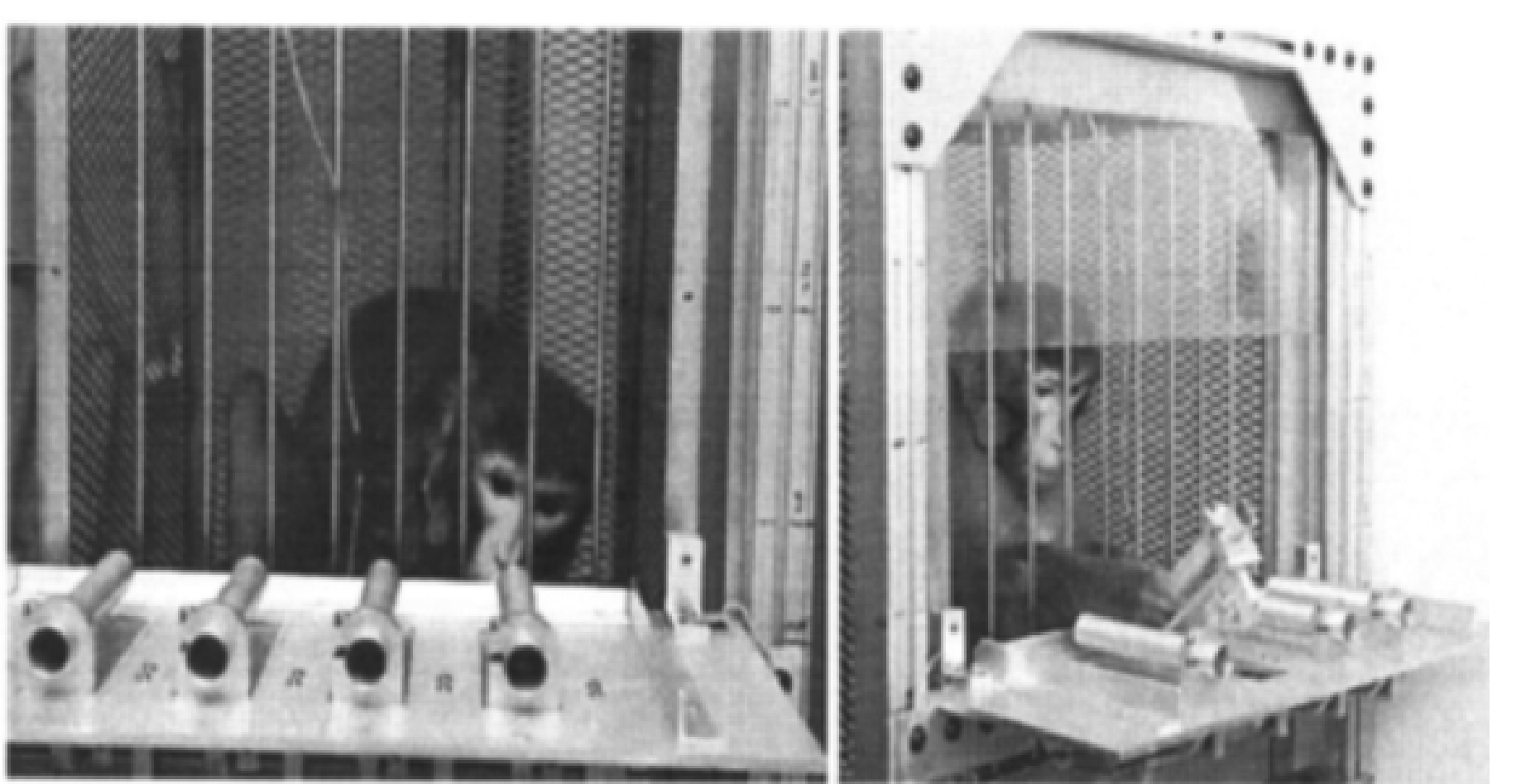

Figure 1. A rhesus monkey is shown looking down tubes, one of which has food (left panel), and selecting the tube containing the reward (right panel). Reprinted From "Rhesus monkeys (Macaca mulatta) discriminate between knowing and not knowing and collect information as needed before acting," by R. R. Hampton, A. Zivin, and E. A. Murray, 2004, Animal Cognition. 7, p. 240. Copyright 2004 by Springer-Verlag. Reprinted with permission. 
allow a monkey to look down the tubes, the tubes initially were raised to the monkey's eye level. During testing, the height of the tubes on seen and unseen trials was moved up or down to encourage looking behavior. Seen and unseen trials occurred in random order, with a transparent screen between the monkey and the experimenter on seen trials and an opaque screen between the monkey and the experimenter on unseen trials. All nine of the monkeys tested looked down the tubes more often on unseen trials than on seen trials. In fact, the monkeys looked down the tubes on almost all of the uneen trials. When monkeys tooked on almost als, they chose the correct tube on $84 \%$ of the trials. On the few trials when they chose without looking on unseen trials, their performance was not better than chance (22\%).

Other research with capuchin monkeys has yielded less convincing evidence of metacognition-like behavior. Using the same procedures as Hampton et al. (2004) used with rhesus monkeys, Basile, Hampton, Suomi, and Murray (2009) found that three out of five monkeys showed significantly more looking down tubes on unseen trials than on seen trimore looking down tubes on unseen trials than on seen tri-
als. A particular problem with capuchin monkeys was their als. A particular problem with capuchin monkeys was their
tendency to look down tubes even on trials when they could see the correct tube baited. Paukner, Anderson, and Fujita (2006) tested five capuchin monkeys on a task with three tubes. Although the monkeys never saw the experimenter bait a tube, tests were carried out in which two of the tubes were opaque and one was transparent on some trials and two of the tubes were transparent and one was opaque on other trials. Thus monkeys could view the food reward in a transparent tube without looking down the tube and could infer the location of food in the opaque tube when it was seen that two transparent tubes were empty. Three of the five monkeys chose the baited tube on nearly all the trials. More monkeys chose the bailed ube on nearly all the trials. More importantly, hever to look frequently and equally down opaque and transparent tubes both when they were baited and empty. The authors sug-
gested that the monkeys may not have understood that the bait seen from above a transparent tube was the same as that bait seen from above a
seen through the tube.

Two explanations of these monkey data as alternatives to metacognition have been offered (Hampton et al., 2004: Basile et al., 2009). One possibility is that monkeys learned to discriminate between the publicly observable cues provided on seen and unseen trials. Thus, they might have learned to look down tubes when they did not see an experimenter bait a tube and to choose a tube immediately when they did see it baited. The problem with this explanation is that the looking behavior appears early in testing and thus it is not clear when such a discrimination would develop. This was particularly the case in the Call and Carpenter (2001) studies, in which several of the apes tested looked down tubes on the first unseen trial. Response competition was considered as a second alternative explanation. The reaching-for-a-tube esponse could have been strong on trials when bait was see and thus interfered with looking behavior. When baiting was not seen, the looking response would dominate. This was clearly not the case with capuchin monkeys, however, because they tended to look down the tubes frequently even on seen trials. Hampton thus concluded that these experiments suggest that "rhesus monkeys discriminate between knowing and not knowing" (Hampton et al., 2004, p. 239) and that " these findings provide equivocal evidence for memory awareness in capuchin monkeys..." (Basile et al., 2009 , p. 169).

Call (2010) has suggested that the tendency of primates to look repeatedly down tubes or to look down tubes they have seen baited may represent a "passport effect", the tendency familiar to humans of rechecking one's luggage to make sure the passport is there before leaving on a trip. As an interesting example of this effect, Call tested a group of apes (orangutans, chimpanzees, gorillas, and bonobos) on a task in which one of two opaque tubes was baited while the subject watched but the opportunity to choose between the tube was delayed between 5 and 120 seconds. The frequency of looking down tubes increased over the delay. Although this might seem like an effect simply attributable to forgetting, the surprising aspect of this finding was that looks at long delays were most often made down the tube containing reward. It appeared that subjects were re-checking the accuracy of their memory, the passport effect.

Call (2010) also examined the effect of motivational variables on information seeking in apes. When hidden food was placed in oblique opaque tubes (tubes formed a $60^{\circ}$ angle with one another), animals had to make more effort to look down the tubes than when straight tubes were used. Looking responses were significantly lower with oblique tubes than with straight tubes. Quality of reward was also found to be important. When a more preferred reward was placed in one of the tubes, subjects looked down tubes more often than when a less preferred reward was placed in more oth on tials when the biring proceduse was visible and both on
hidden.

Marsh and MacDonald (in press-a) report information seeking in three orangutans using a modified version of the Call and Carpenter (2001) task An orangutan chose Call Call and Care las tas tray, so that an orangutan could bend down and look up ove $90 \%$ of the over $90 \%$ of the trials when the baiting process was hidden foe which con less than $20 \%$ of the tials when they could see which container was baited. In further tests, the subjects were offered a choice between three opaque container on some trials, but could choose only one opaque container on other trials, with baiting hidden from view in both cases. All three subjects looked more often in the three-cup condition than in the one-cup condition. Looking also occurred less often on hidden baiting trials when the orangutans were shown one opaque baited container and two transparent containers than on trials on which they were shown two opaque containers (one baited) and one transparent container. These fontainers (one baited) and all and Carpenter's (2001) obfindings are rescols obard and MacDonald argu from these experiments that orang whenever they encountered an opaque container.

In a further article, Marsh and MacDonald (in press-b) reported that variables which manipulated effort, risk, and payoff all affected information seeking in orangutans. Effort was manipulated by varying the degree to which orangutans had to bend down to look under containers; the more effort that was required, the less often apes looked under the transthat was required, the less often apes looked under the trans-
parent tray. Risk was varied on hidden baiting trials by giving the subjects different trials on which they had to choose among two, three, or four containers, only one of which contained the reward. Thus, random chance should yield the reward on $50 \%, 33 \%$, and $25 \%$ of the trials as the number of containers was increased. The percentage of looks increased as the risk or number of containers increased. Another way of looking at this finding is that the subjects obtained more information for a looking response as the number of containers increased, a look on two-, three-, and four-containe trials yielded $1,1.6$, and 2 bits of information, respectively Finally, the payoff for a looking response was varied by using half a piece of candy as the hidden reward on some sesing half a picce of candy as the hidden reward on sone sessions and two pleces of candy as the hidden reward on other essirs. Or thes than on low-reward thiss. As in Calls (2010) experments, motivational factors clearly affected the readiness of orangutans to seek information. It should be noted that the tendency of apes to look more often when a better or greater reward was hidden argues against the idea that looking was in competition with reaching. Better rewards should more strongly reinforce a reaching response and not a looking response.

Yet another example of information seeking in monkeys was revealed in a recent matching-to-sample study (Beran \& Smith, 2011). After learning to match comparison stimuli to sample stimuli shown on a monitor, monkeys were confronted with a task in which sample stimuli were occluded but comparison stimuli were visible. Rhesus macaque monkeys could move a cursor to a cue that removed the occluder and allowed them to match the sample correctly or they could choose between the comparison stimuli without eing the sample. Five out of eight monkeys tested chose to reveal the sample stimulus before responding to the comparison stimuli, and this preference for information appeared within the first session of testing. Capuchin monkeys tested this task showed some success but did not perform as well as macaque monkeys.

Do Pigeons Show Information Seeking?

Could evidence of information seeking be found in nonprimate animals? Experiments with pigeons were carried out in our laboratory to address this question (Roberts, Feeney, McMillan, Macpherson, Musolino, \& Petter, 2009). The procedure was similar to that described for testing monkeys in the Beran and Smith (2011) studies. Figure 2 shows the two types of trials on which pigeons were trained and tested.

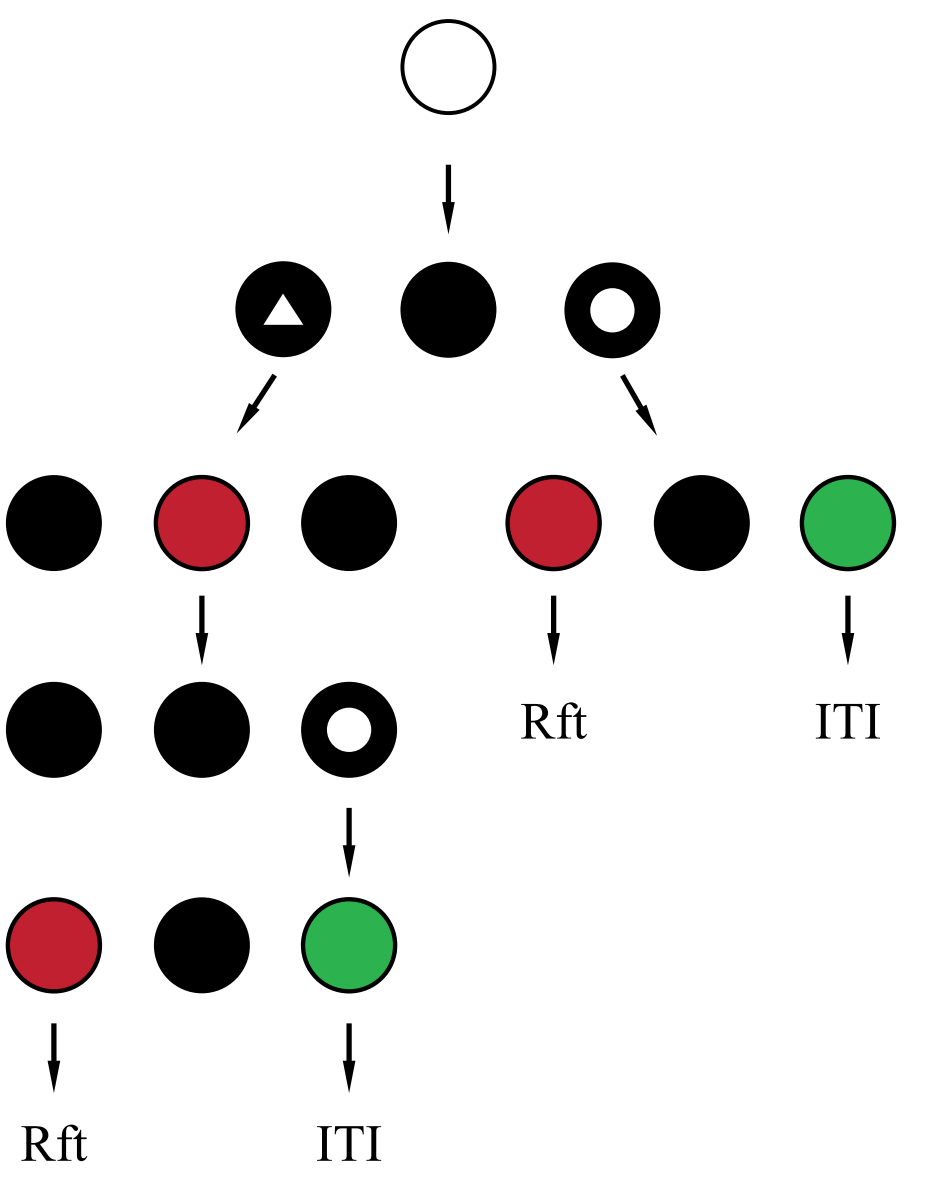

Figure 2. After pecking a white center key, a pigeon then chooses either to peck the triangle, yielding sample information and a delayed matching test, or to peck the circle and go directly to the matching test, or to peck the (Columb livia) study for a test?" by William A Roberts, Miranda C. Feeney, Neil McMillan Krist Mac Pherson, Evanya Musolino, and Mark Petter, 2009, Jounsol of Experiment Psychology: Animal Behaior Processes, 35, p. 131. Copyright 2009 by the American Psychological Association. Adapted with permission 
On half the training trials, a peck to the white center key lit the left key with a triangle. A peck on the triangle yielded red or green sample stimulus for 5 seconds, followed by presentation of a circle on the right key. A response to the circle yielded matching and nonmatching red and green keys, with choice of the matching key yielding reinforcement. Thus, pigeons learned delayed matching to a high level of accuracy on trials that required a peck on the triangle cue. On the other half of the training trials, pigeons were required to peck a circle on the right key immeditely after required to eck cecter and green with $50 \%$ pielding reinforcement with $50 \%$ probability. Eventually, pigeons were given tes probe trials, interspersed among the forced training trials, on which they chose between the triangle and circle. The logic of this procedure was to allow the pigeon to choose between seeking information (the sample stimulus) or to go directly to the comparison test stimuli without seeing the sample. Importantly, pigeons could match correctly and obtain reinforcement on about $90 \%$ of the test trials by choosing to see the sample but could obtain reinforcement on only $50 \%$ of the test trials by choosing to go directly to the test stimuli.

The results of this experiment are shown over 10 session in the top panel of Figure 3 (Experiment 1a). The open circles curve shows the percentage of trials on which pigeon chose to look at the sample before making a choice between test stimuli. This curve starts at about $20 \%$ but quickly drops to virtually $0 \%$ choice of the sample stimulus alternative. Thus, pigeons strongly preferred to go directly to the test, even though it meant they would receive reinforcement at no more than a chance rate. One reason for this strong preference for the test stimuli may be that choice of the triangle key meant pigeons had to spend 5 seconds in the presence ke exiso stimuli. As in self-contor or delay-disconting experiments, pigeons may prefer an immediate opportunity to obtain reinforcement $50 \%$ of the tine over a delayed opportunity to obtain reinforcement with $90 \%$ probability. To test this possibility, a test delay of 5 seconds was introduced between choice of the circle and presentation of the test stimuli Now, pigeons experienced equal delays to opportunity for reinforcement for choice of either the triangle or circle. The findings shown in the middle panel of Figure 3 (Experiment 1b) indicate that choice of the triangle (sample key) rose to about $50 \%$ of the trials. The test delay then was shifted to 7.5 seconds, longer than the delay imposed by viewing the sample, and pigeons developed a strong preference for the sample. To see if this preference held when delay to the test stimuli was equated, the test delay was returned to 5 econds; pigeons maintained a strong preference for the triangle key that yielded the sample stimulus. The question then was whether pigeon would contine to take senpe
Experiment $1 \mathrm{a}$

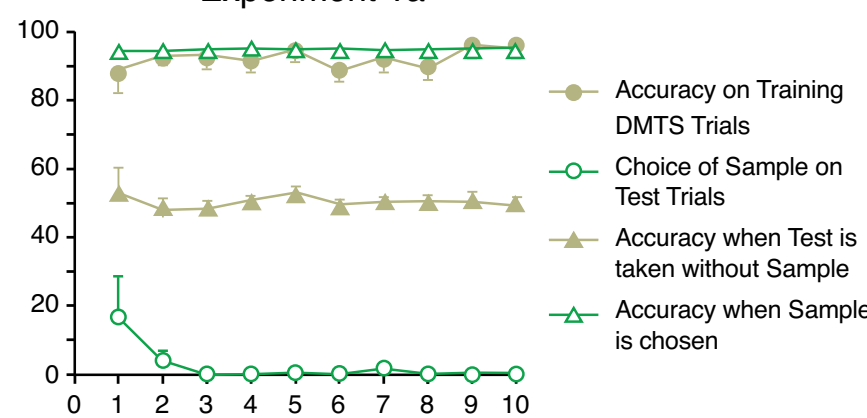

Experiment 1b

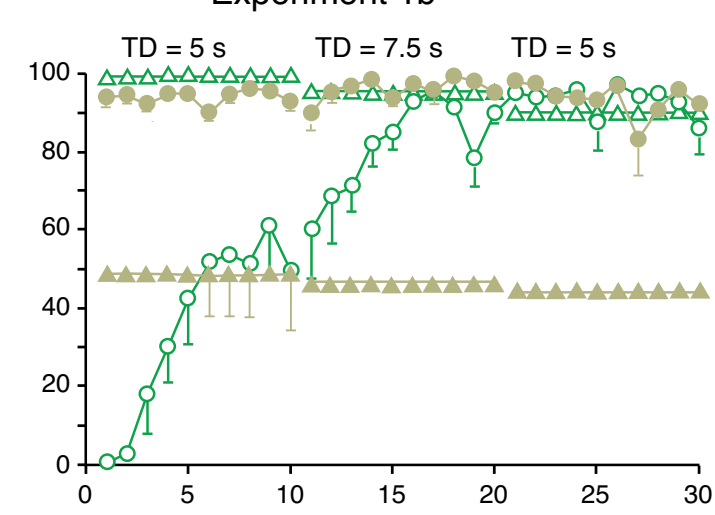

Experiment $1 \mathrm{c}$

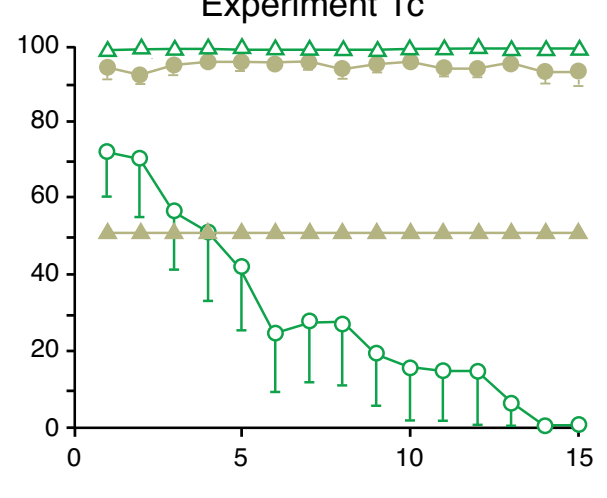

Sessions

Figure 3. Data from experiment shown in Figure 2 when choice of the circle led directly to test stimuli (Experiment la), when test delays of different length were introduced between pecking the circle and the test (Experiment $1 b$ ), and when subjects were returned to an immediate test after pecking the circle (Experiment 1c). Reprinted from "Do pigeons (Columba livia) study for a test?,” by William A. Roberts, Miranda C. Feeney, Neil McMillan, Krista MacPherson, Evanya Musolino, and Mark Petter, 2009 Journal of Experimental Psychology: Animal Behavio Processes, 35, p. 133. Copyright 2009 by the American sychological Association. Reprinted with permission.

information when the test delay was reduced to 0 seconds, as in initial testing. The bottom panel of Figure 3 (Experiment $1 \mathrm{c}$ ) shows that they clearly did not. As soon as the test delay was shifted back to 0 seconds, pigeons began to shift to a preference for the circle key and immediate presentation of the test stimuli.

These initial studies then discovered little evidence to suggest information seeking in pigeons. In an attempt to provide a more sensitive test, Roberts et al. (2009, Experiment 3) trained pigeons to perform simultaneous matchingto-sample, in which choice of the side key that matched a simultaneously present sample stimulus on the center key was reinforced. Test trials were then interspersed among training trials to test for information seeking behavior. The test tria alternatives are shown in Figure 4. After pecking a white center key, a pigeon was confronted with red and green side keys and the white center key. It could either respond to one of the side keys and receive reinforcement on $50 \%$ of the or the white center key (information seeking) to reveal the sample stimulus. The cor-

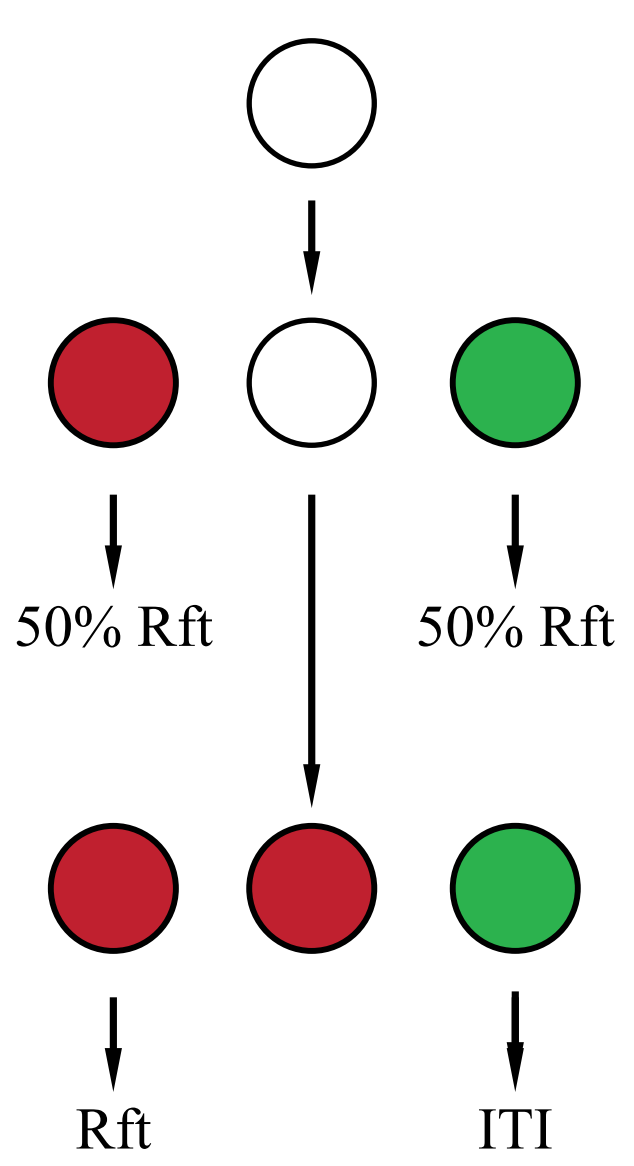

Figure 4. After pecking a white center key, a pigeon can peck red or green side keys or peck the white key one can time to present a sample color on the center key and compre a simultaneous matching-to-sample test. Adapted from a simultaneous matching-to-sample test. Adapted from "Do pigeons (Columba livia) study for a test.," by William A. Roberts, Miranda C. Feeney, Neil McMillan, Krista MacPherson, Evanya Musolino, and Mark Petter, 2009. Journal of Experimental Psychology: Animal Behavior Processes, 35, p. 136. Copyright 2009 by the American Psychological Association. Adapted with permission ect comparison stimulus was chosen about $80 \%$ of the time when the sample was seen. The results did not encourage the hypothesis that pigeons seek sample information. They chose to make the additional peck on the white center key and view the sample on only $50 \%$ of the trials. Choice of the sample stimulus did not rise above 50\% over 20 sessions of esting.

It may be argued that even the extra second or so it took pigeons to make an extra peck on the white center key, view the sample, and choose the matching comparison was too long a delay to endure relative to immediate choice of a comparison stimulus (Zentall \& Stagner, 2010). In a new set of experiments, Zentall and Stagner found evidence suggesting that pigeons seek relevant sample information in a delayed matching-to-sample task. At the beginning of trial, pigeons could peck either a plus or a circle on of a ent side keys. A peck on the plus key led to a 5-s pesentaent sick keys. A peck on the plus key led to a s-s presentation of a red or green sanple on the center key, followed by choice betws oen ma pigen and side keys. Thus, a pigeon could be correct on all trials by choosing the matching key. If a pigeon pecked the circle, however, a yellow or blue sample appeared for $5 \mathrm{~s}$, followec by red and green comparison stimuli. Because choice of the red or green comparison stimulus was not correlated with the yellow or blue sample, the sample was non-informative and pigeons could only earn 50\% of the reinforcers. On probe trials that offered pigeons a choice between the plus and circle, pigeons learned to prefer the plus stimulus that led to an informative sample stimulus. When the outcomes of pecking the circle and plus were reversed, pigeons continued to track the informative sample alternative. Although these findings may suggest that pigeons chose information, one concern is that they received more reinforcement for (ont for che con than for chosing the key that led to a non-ifome sample. Thus, the preference shown conld reflect choice of a higher probability of reinforcement and not of information. In fact, Zentall and Stagner (personal communication) recently have found that pigeons given a choice between sample stimul that can and cannot be matched to comparison stimuli show no preference when the probability of reinforcement is equated between these choices.

We carried out a further experiment to examine the possibility of information seeking in pigeons. The design of this experiment involved reinforcing pigeons for making a response that yielded information which could be used to obtain further reinforcement. Following this training, the reinforcement was withdrawn for the initial response to see whether pigeons would abandon this response or would continue to respond in order to obtain information. The procedure used is shown in Figure 5. Each trial for groups of Experimental $(\mathrm{n}=5)$ and Control $(\mathrm{n}=5)$ pigeons began with 

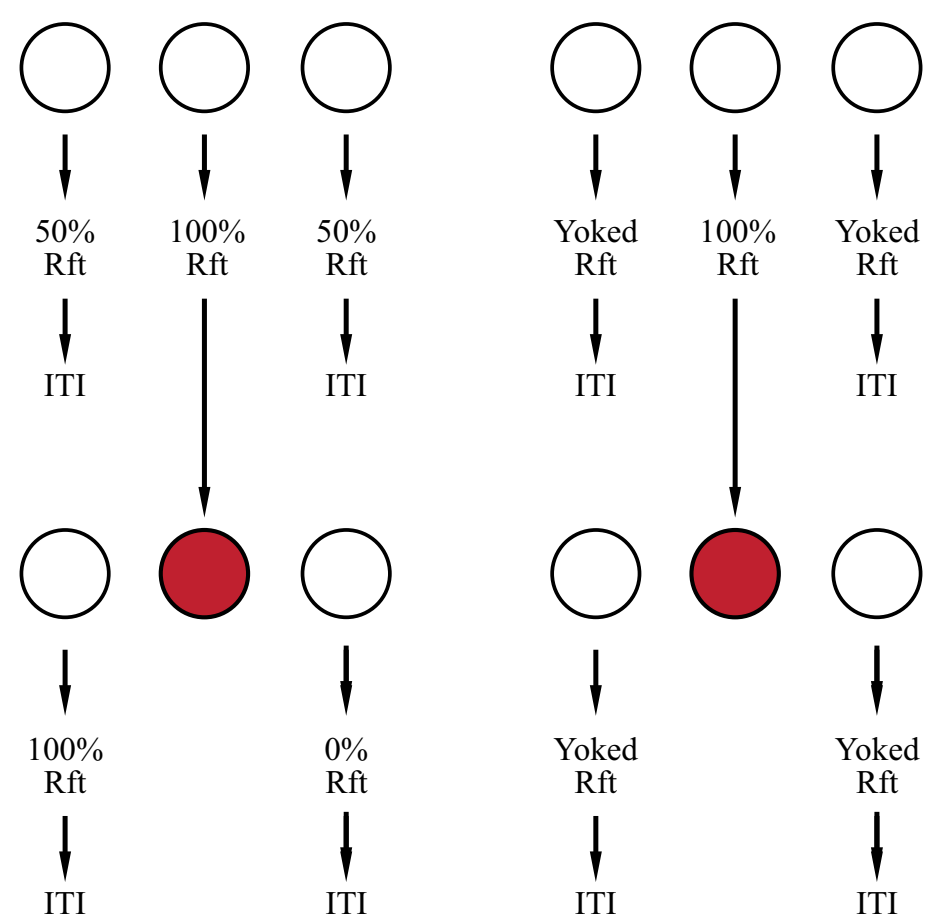

Figure 5. Experimental and control pigeons initially choose between three white keys, with a peck on the center key yielding $100 \%$ reinforcement and pecks on either side key yielding random 50\% reinforcement. Choice of the center key also provides a red or green center key that can be matched to a correct side key by experimental subjects (information) but not by control subjects (no information).

the presentation of three white keys. For Experimental pigeons, a peck on either side key yielded 3 seconds of grain reinforcement on $50 \%$ of the trials. A peck on the center key, however, yielded $100 \%$ reinforcement and led to a further presentation of the three lit keys. The center key was lit red on half the trials and green on half the trials, in random order, and the side keys remained white. For three pigeons, the red center key signaled that the left key must be pecked for reinforcement and the green key signaled that the right key must be pecked for reinforcement. These contingencies were reversed for the other two pigeons. Thus, pecking the initially white center key provided both reinforcement an information for experimental birds. Control pigeons also received 100\% reinforcement for pecking the cents also key and advanced to a red or geen center key. However cey fir the birs, he colo of the center key was not informative because it was not correlated with reinforcement given for pecking the white side keys. Rather, reinforcement for pecks on the side keys was yoked to the performance of the experimental pigeons. Each control pigeon was yoked to an experimental pigeon in such a way that the probability of reinforcement on each side key was the same as the percent-
age of reinforcement the experimental pigeon had received
After 45 sessions of training with 48 trials per daily session, pigeons in both groups reliably pecked the center key or reinforcement. Over the final five sessions of training, the experimental group pecked the center key on $96.1 \%$ of the trials and the control group pecked the center key on $95.9 \%$ of the trials. When the center key was pecked on these trials, and the informative center key was revealed, experimenta pigeons chose the correct side key on $87.8 \%$ of the trials. On the few trials when a side key was chosen without a peck on the center key, the percentage of reinforced trials was 53.9\%.

Extinction was introduced over the next 10 sessions by omitting reinforcement for pecks on the white center key. It can be seen in Figure 6 that pecks on the center key declined to a low level of pecking over these sessions in the experimental and control groups. Extinction of center key pecks also led to a decline in correct matching accuracy on trials when the center key was pecked by experimental pigeons. Choice of the correct side key on these trials for the fina five sessions of extinction was only $65.4 \%$. These result clearly fail to support the idea that $65.4 \%$. These results (five cobtain informatio

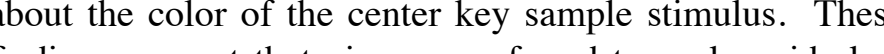
findings suggest that pigeons preferred to peck a side key inmediately for 50\% reinforcement rather than peck the center key for information that could lead to a higher probability of reinforcement.

At this point, we introduced a manipulation to make the

\section{ర్ల}

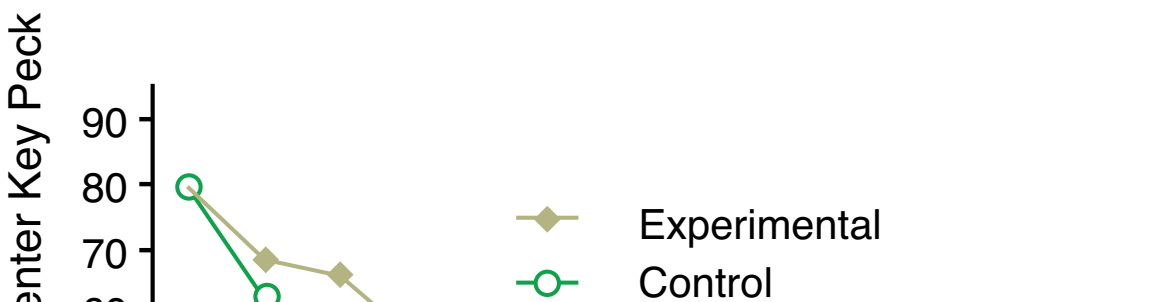

Figure 6. Extinction of center key pecking in experimental and control pigeons when reinforcement was withheld for pecking the white center key. pigeons pay a higher price for side key choices in order to ing improved appreciably in the experimental pigeons, with see if this would influence center key pecking and matching pigeons now matching the sample correctly on $97.9 \%$ of the accuracy. We gradually raised the fixed ratio of pecks re- trials over the final five sessions.

quired on the side keys from FR1 to FR 20 over 37 sessions. This manipulation had a dramatic effect on three of the experimental pigeons, as it produced consistent pecking on the white center key. The two remaining experimental pigeons continued to prefer to peck a side key initially. The effect of an initial side key peck was to reduce the delay to reinforcement (on reinforced trials) by $2-3$ seconds because it took the pigens this pigeons this long key response based on the color of the center key. To equate delay to reinforcenent, we added this extra time to the end of the 20 pecks required on the side key when pigeons made an immediate side key choice but not when they made the center key choice and responded on the basis of the center key information. After this manipulation, the remaining two pigeons strongly preferred to peck the center key before choosing a side key. Control birds subjected to the same increases in side key peck ratio and equated time to reinforcement showed little increase in center key pecking. The data for individual birds are shown in Figure 7, with percentage of trials with pecks to the center key over the final five trials

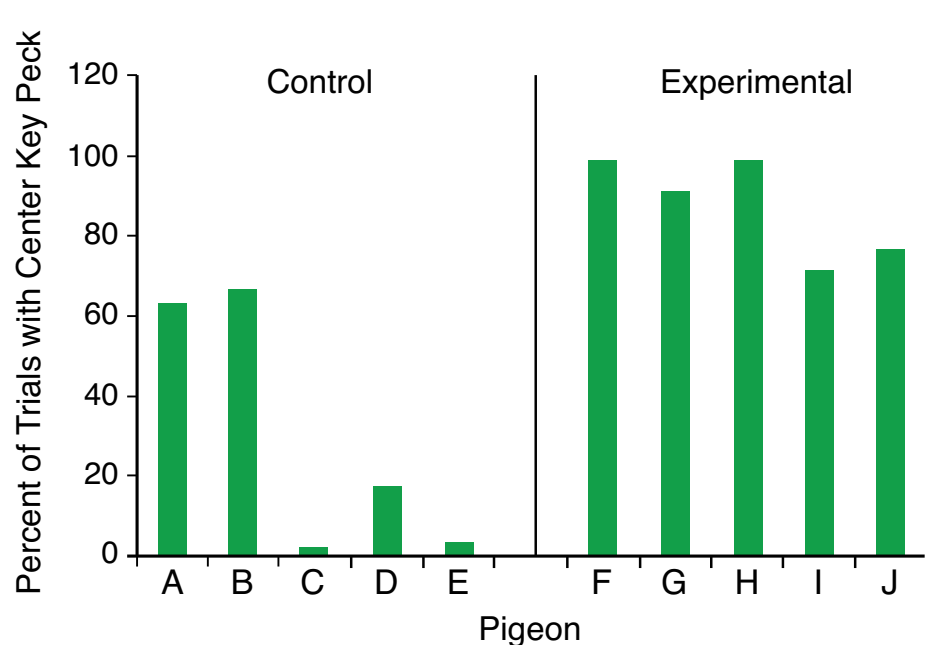
Pigeon

Figure 7. Percentage of pecks on the white center key by experimental and control pigeons when the price for response to the test side keys was FR20 and the delay to trial outcome was equated between tests taken with and withou viewing the center key sample stimulus.

shown for control birds in the left panel and for experimental birds in the right panel. Experimental birds' trials with a center key peck increas from $20.7 \%$ one of last five sesion last five sessions shown in Figure 6 to $87.5 \%$ for the dat shown in Figure $7,(4)=17.56, p<.01$. Data over the same sessions for control birds increased non-significantly from $21.1 \%$ to $30.6 \%, t=1.01, p>.05$. The difference between
the control and experimental birds shown in Figure 7 was the control and experimental birds shown in Figure 7 was
significant, $t(8)=3.72, p<.01$. Accuracy of sample match-
Although the initial findings of Roberts et al. (2009) failed to yield evidence of information seeking in pigeons, the new experimental designs and procedures used by Zentall and Stagner (2010) and in the new study reported here indicate that pigeons will respond for information that can be used to obtain reward. In both cases, equalizing the delay to reinforcement for informative and non-informative choices seems to yield a preference for the informative choice.

\section{Rats Choose to Know}

One difference between the pigeon experiments just described and the ape and monkey experiments reviewed (Call is that pigeons were confronted with keys they had to peck in order to advance within a trial. The nonhuman primates response (looking down tubes) appeared to be more of an untrained voluntary or purposeful response made to obtain information. In an experiment carried out in our laboratory, we attempted to induce rats to make an information seeking response that had this more voluntary nature.

Five rats were trained and tested in the T-maze shown in Figure 8. They were trained to make a successive discrimination between black and white panels placed at the end of the starting alley where the rats had to choose between a

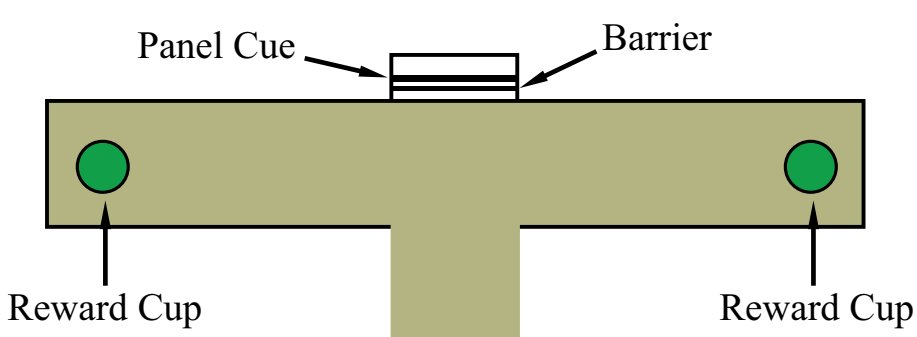

Reward Cup Reward Cup \& Carpenter, 2001; Hampton et al., 2004; Basile et al., 2009)
Figure 8. Diagram of the T-maze used to study information seeking in rats. The panel cue (black or white) indicated the location of reward. The question of interest was whether rats would rear up and look over the barrier to see the brightness of the panel. 
left or right turn. Thus, for one rat, a black panel would $=7.91, p<.01$. Performance did not exceed chance with the indicate that a right turn led to food at the end of the alley $75 \%$ barrier, $t(4)=1.63, p>.05$, or the $100 \%$ barrier, $t(4)=$ and a left turn led to no food, and, conversely, a white panel 0.00

would indicate that a left turn led to food at the end of the alley and a right turn led to no food. An important aspect of this experiment is that the cue panel was recessed somewhat back from the choice point in the maze. Thus, barriers that blocked the rat's view of the panel could be placed in front of it. After rats had learned to respond accurately to the cue panels, barriers that blocked the lower 25\%,50\%, the cue 列 . sions. Events ally, a barier that blocked $100 \%$ of the pane was put in place. Although a rat approaching the barrier on all four feet could not see the cue panel, by rearing up on its hind legs it could look over the barrier and see the brightness of the cue panel. Tests that gradually increased the height of the barrier were used to encourage rats to rear up and peer at the top of the panel and to eventually look over it when the full barrier was used.

The question asked in this experiment was whether rats, like monkeys and apes looking down tubes, would make the novel response when a barrier was in place of rearing up a the choice point in the T-maze to access critical information that would allow them to make an informed choice. B accessing the cue panel brightness, a rat could potentially obtain reward on every trial. Failure to seek out cue panel information, however, would mean that it should only be
able to obtain reward at around the chance level of 50\%.

Rats learned the discrimination over 33 sessions, with black and white floor cues initially used and then gradually removed. Over the final eight sessions, rats were trained for 10 trials each session with only the panel cues present, rats chose the correct arm on over $90 \%$ of the trials. On test sessions, rats continued to receive 10 trials per session, with the black and white cues each used on five trials. Each rat completed four sessions with the $25 \%$ barrier, five session with the $50 \%$ barrier, three sessions with the $75 \%$ barrier, whe $50 \%$ baier, the sessing with the $75 \%$ bater, at to rear up a look over the barier. Ane accorded.

Figure 9 shows the percentage of correct choices made during sessions of testing at each barrier height. The $0 \%$ bar represents performance over the last 5 sessions of training with no barrier present. It can be seen that accuracy of g w way within subjects analysis of variance (ANOVA) yieneway within subjects analysis of vanian (ANOVA) yielded a significant effect of barrier height, $F(4,16)=46.84, p<$
001 . Single-sample t-tests were performed to compare performance against the chance level of $50 \%$ at each barrier formance against the chance level of $50 \%$ at each barrier height. Rats performed at levels significantly better than
chance with no barrier, $t(4)=7.91, p<.01$, with the $25 \%$ chance with no barrier, $t(4)=7.91, p<.01$, with the $25 \%$
barrier, $t(4)=13.07, p<.01$, and with the $50 \%$ barrier, $t(4)$

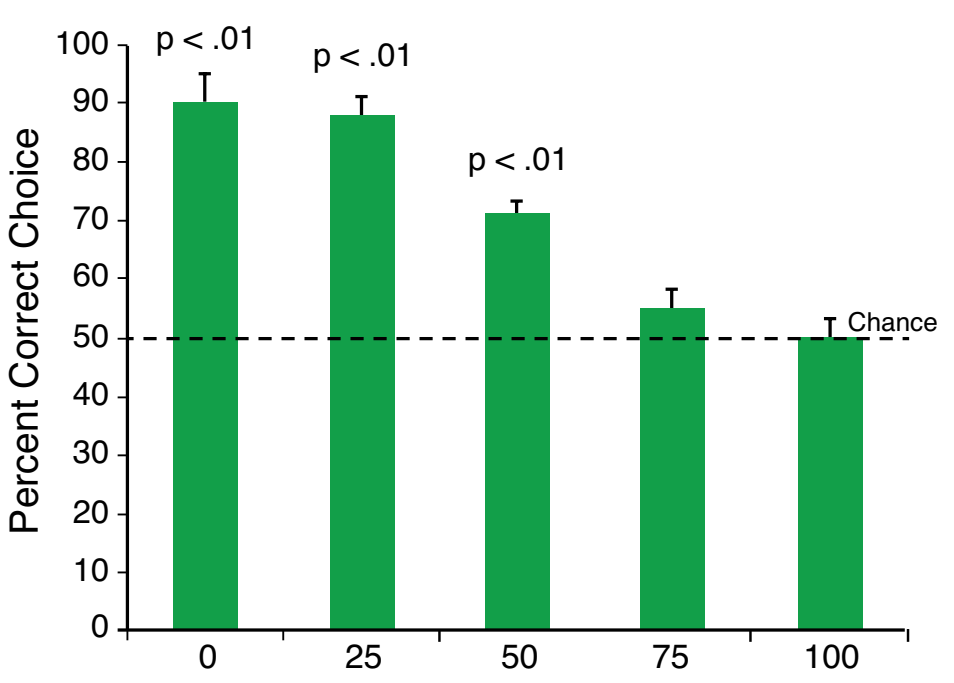

Barrier Height as Percent of Maximum

Figure 9. Percentage of correct arm choices made by rats at different heights of the barrier blocking visual access to the panel cue.

Observation of the rats failed to reveal any trials on which a rat paused at the choice point and reared up to look over a barrier. Rats appeared to base their choices on whatever they could see of the cue panel as they approached the choice point on four feet. Thus, no evidence was found to suggest that rats made a voluntary or novel response to obtain inormation, as had been seen with nonhuman primates. The ailure of rats to make this observing response at the choice

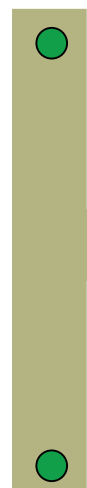
ing with rats. Notice that the initial choice of the formation on one side of the maze and no information on the other side of the maze. and left arms with black a secondary choice between right point does not, however, lead inevitably to the conclusion Figure 8. Notice that two additional choice points and althat rats would never make a response that provides infor- leys have been added to the maze at the ends of the primary mation necessary for a correct choice. Although rats showed choice alley. Black and white cue panels were affixed to the no evidence of understanding the need to look behind the walls of each secondary alley at the choice point between a barrier, it is possible that they did not understand that they left or right turning response. On one side of the maze, the could obtain information by making a rearing response. black and white cues were informative because they indicated the correct turn for reward. Thus, a black cue might

We carried out a further experiment with rats to see if they indicate that a right turn led to reward in the cup at the end might make an information-seeking response in a different of the right arm, while a white cue indicated that a feft tur suggested information seeking, rats were trained in a task in which they had to make a choice between responses that led When rats entered the non-informative arm, they also en. The starting alley point. However, these cues were not correlated with the lo-

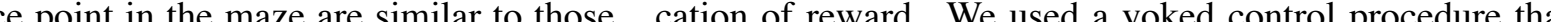
for the maze used in the preceding experiment, shown in equated the number of rewards received on the informative

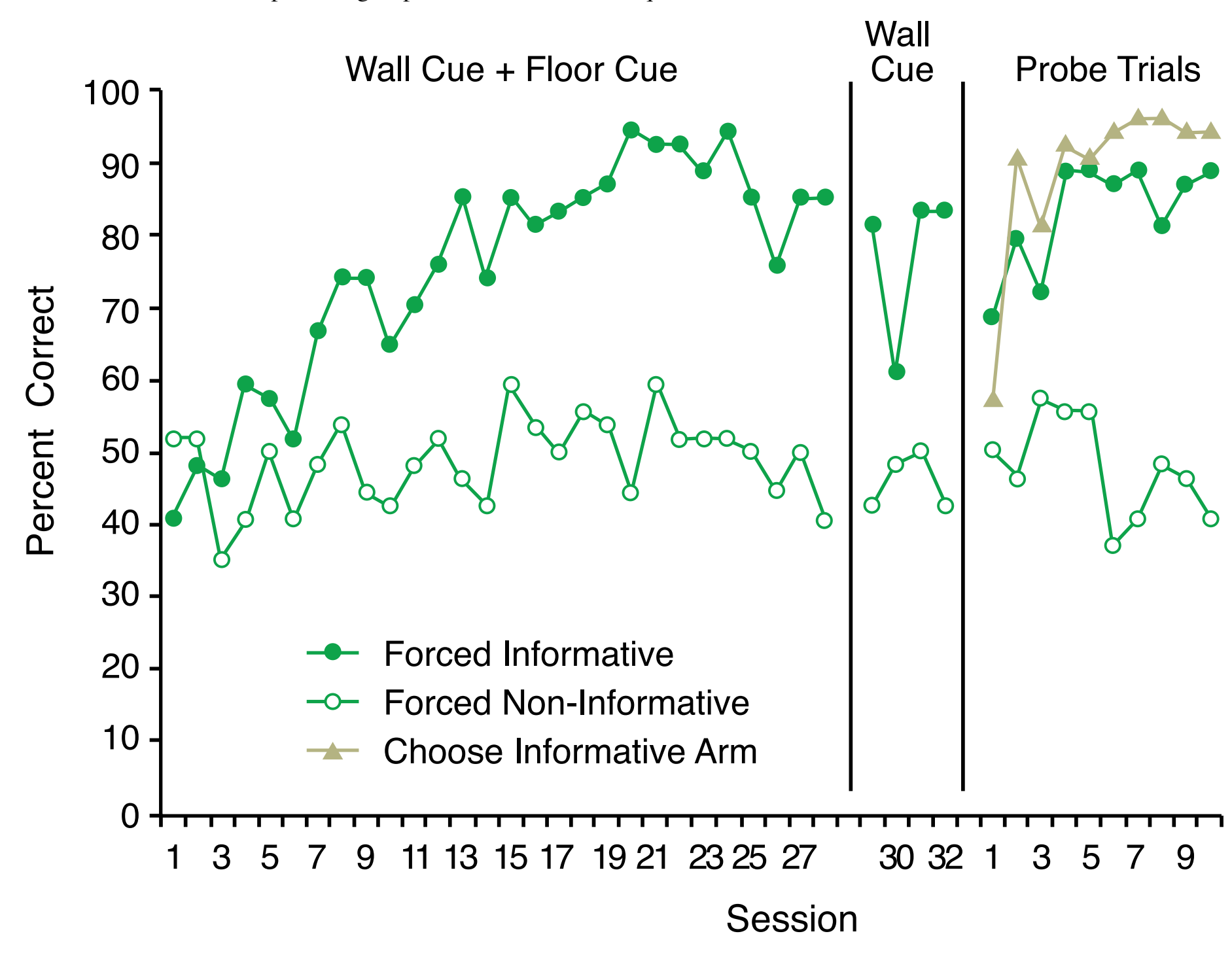

Figure 11. Percentage of correct choices shown over training sessions and during probe trials. The left and center panels show choice of the correct secondary arm on forced trials during which the panel (wall) cues were informative and noninformative. The right panel shows that rats strongly preferred to enter the informative arm (triangles) on free choice trials and that rats continued to choose the correct secondary alley when they chose the informative arm but not when they chose the non-informative arm. 
and non-informative sides of the maze. We rigged the experiment so that both reward cups on the non-informative side contained food or no food on the same number of trials as rats made correct and incorrect choices on the informative side of the maze.

Nine rats were trained over a number of sessions on forced rials that required turns to the informative and non-informative sides of the maze. Once they had learned to make correct choices at a high level of accuracy on the informative side, they were tested over sessions in which probe test trials were inserted among the forced training trials. On probe trials, both arms were open at the primary choice point, and rats could choose between the informative and non-informative arms of the maze. The question of primary interest was whether rats would show a preference for the infort was side of the maze.

Rats' performance over 32 training sessions and 10 test sessions with probe trials is shown in Figure 11. For the first 28 sessions, floor and wall cues were present in the secondary alleys. Only the wall panel cues were present on Sessions 29-32. The filled circles curve shows that on Sessions 29 -32. The the informative side of the maze, when the wey learned to choose the correct arm at the secondary choice point at around $90 \%$ accuracy by sessions $20-28$ with the wall cue and floor cue both present. When the wall cue only was present on sessions $29-32$, rats continued to choose accurately at around $80 \%$.

The open circles curve plots the percentage of trials on which rats made choices on the non-informative side that would have been correct on the informative side of the maze. Henceforth, these will be referred to as nominal choices. Thus, if a rat had to turn right if the cue was black and le if the cue was white on the informative side, each turn to the right when the cue was black and turn to the left whe the cue was white on the non-informed side was counted as a nominally correct choice. It can be seen that rats' performance on forced trials to the non-informative side stayed around 50\% throughout training and testing. Rats did not apply the rules for correct choices on the informative side to their choices on the non-informative side.

An ANOVA was performed on percent correct choices that contained Sessions 1-28 as one factor and side of the maze (Informative versus Non-Informative) as the other Significant effects of session, $F(27,216)=4.72, p<.01$, side of the maze, $F(1,8)=230.80, p<.01$, and the Session $\mathrm{x}$ Side of the Maze interaction, $F(27,216)=3.29, p<.01$, were revealed. Mean nominally correct choices over all 28 sessions on the non-informative side of the maze (48.7\%) did not exceed $50 \%$, but mean correct choices over $20-28$ on the informative side of the maze $(88.3 \%)$ signifi- cantly exceeded $50 \%, t(8)=23.37, p<.01$. On Sessions $29-32$, with only the wall cue present, there was a significan difference between correct choices on forced informative trials and nominal correct choices on forced non-informative rials, $F(1,8)=42.72, p<.01$. The mean on informative trials $(77.3 \%)$ significantly exceeded $50 \%, t(8)=9.24, p<.01$, but the mean on non-informative trials $(45.83 \%)$ did not.

During the 10 test sessions shown on the right side of Figure 11, there was an initial drop in choice of the correct arm on forced informative trials, but rats resumed a high leve of correct choices by Session 4. They continued to show indifference between nominally correct and incorrect arms on forced non-informative trials. Of primary importance, ree-choice probe trials, rats chose the informative arm on $57.4 \%$ of the trials on Session 1 but then showed a maked prefere $f$ the informative side of the maze on Sesions 2-10. Figure 12 shows the nean dat for exch chice over est Sessions 1-10. The mean data for each choice over hows prons 1-10. The bar on the left side of the figure phe informative arm. Every rat profe , the informative side was chosen on $88.9 \%$ of the probe thals, and this value significantly exceeded the chance leve of $50 \%, t(8)=23.34, p<.01$. On forced-choice trials, rats continued to choose the correct secondary arm significantly bove the chance level when forced to the informative side $(83.1 \%), t(8)=12.76, p<.01$, but when forced to the noninformative side did not choose nominally correct arms

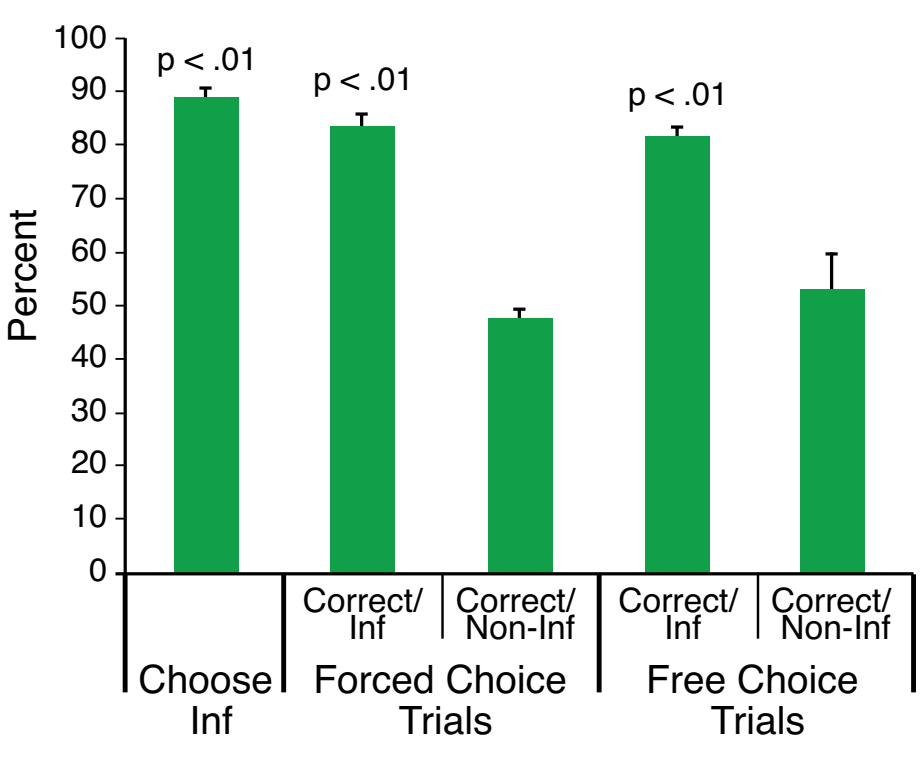

Figure 12. Mean performance over the 10 sessions containing probe trials shown in the right panel of Figure 11. The left bar shows the percentage of probe trials which rats chose the informative arm. Percentage of correct choices when the informative arm was entered and percentage of nominal correct choices when the noninformative arm was entered are shown for forced choice trials and for free choice probe trials. a level above chance (47.8\%). The final set of bars on the right side of Figure 12 shows choice accuracy on probe trials when rats chose the informative and non-informative sides of the maze. When the informative side was chosen, correct choices at the secondary choice point $(81.3 \%)$ significantly exceeded chance, $t(8)=14.12, p<.01$. On the minority of trials when choices $(53.2 \%)$ did not significantly exceed chance, $t(8)=.51, p>.05$.

Although rats failed to make a novel rearing response to obtain information in the first experiment, when given a information and the other of which of which led to useful the ins maze in the second experinent. Futherme rats were sensitive to the conelation between cues and the rewarded choice on the informative side of the maze and to the lack of corelation between cues and the rewarded choice on the non-informative side of the maze. In similar fashio to the pigeon experiment described, rats given a choice between informative and non-informative cues choose informative cues.

Information Seeking in Dogs

Dogs may be an excellent choice of a species in which to look for evidence of memory awareness among non-primate animals. Dogs have evolved from ancestral wolves over the last 10,000 to 15,000 years under human domestication pressure (Csanyi, 2000; Vila et al., 1997). As a consequence, they have developed traits highly adapted to life among huthey have developed traits highly adapted to life among humans, including communicative, cooperative, and attach ment behaviors (Hare \& Tomasello, 2005, Miklosi, 2007 ; Miklosi, Topal, \& Csanyi, 2004). Possibly, increased dependency on human guidance in dogs has made them more sensitive to their own lack of knowledge.

In a previous study of cue-seeking behavior in dogs, Brauer, Call, and Tomasello (2004; Experiment 3) had dog choose one of two boxes by pressing a lever, with food reward in only one of the boxes. On seen trials, the dog viewed the experimenter baiting one of the boxes and chose this box on about $90 \%$ of the trials. On unseen trials, however, a barrier prevented the dog from seeing which box wa baited. The dog could find the location of the food, however by approaching each box and looking through a transparent Plexiglas window before making its choice. Dogs almost never checked the window before pressing a lever and thus were rewarded on unseen trials at only a chance level.

McMahon, Macpherson, and Roberts (2010) trained dogs to make a visual discrimination and then gradually altered the cues to find out if dogs would seek information by moving to a new spatial position. As shown in Figure 13, six
Train

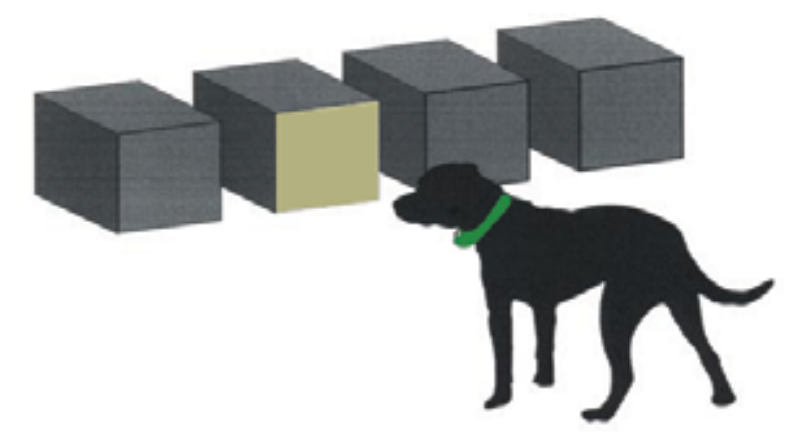

Test

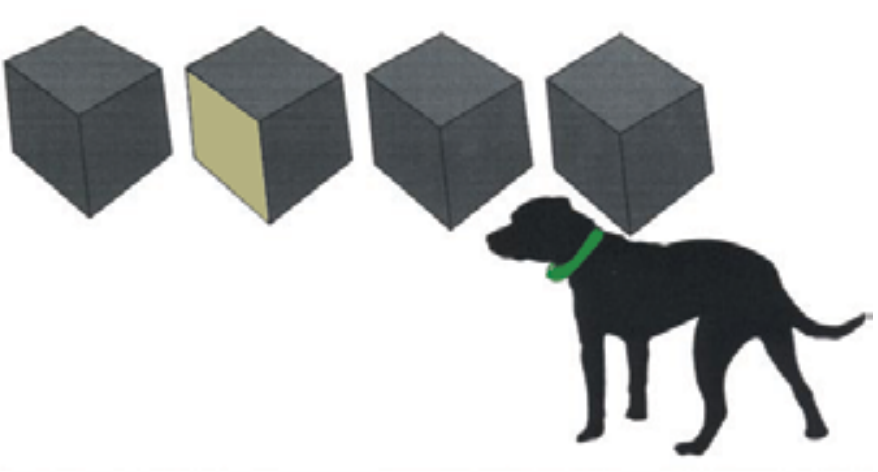

Figure 13. A dog is trained to choose among four black boxes, with the correct (baited) box containing a white face. On test trials, the boxes were rotated from $0^{\circ}$ to $135^{\circ}$ to find out if dogs would re-orient themselves to a position where they could see the white box. Reprinted from "Dogs choose and informant: Metacognition in canines," by Shannon 2010 Be Krista Macpherson, and William A. Roberts. by Elsevier. Reprinted with permission..

dogs were trained to repeatedly choose one box among four, with food reward placed under only one box. The boxes were painted black, with the exception of one box that had white face. The white box always contained food and was andomly placed in different locations from one trit to the next. Initially, dogs chose between only two boxes. Addiext. Intially, do added until the dogs were relibly choosing the white box significanty above chance expectancy $25 \%$ correct). As shown in the test panel in Figure 13, (25) degrees from rotated progressively different numbers of Our intert in this miniputation was to see wessions. would was wile. As a position where they could see which box . (4) 14. At $45^{\circ}$, the white face could be seen from the starting position used in training, and dogs continued to choose the white box significantly above chance. At $90^{\circ}$ and $135^{\circ}$ rotation, however, dogs were no longer statistically better 


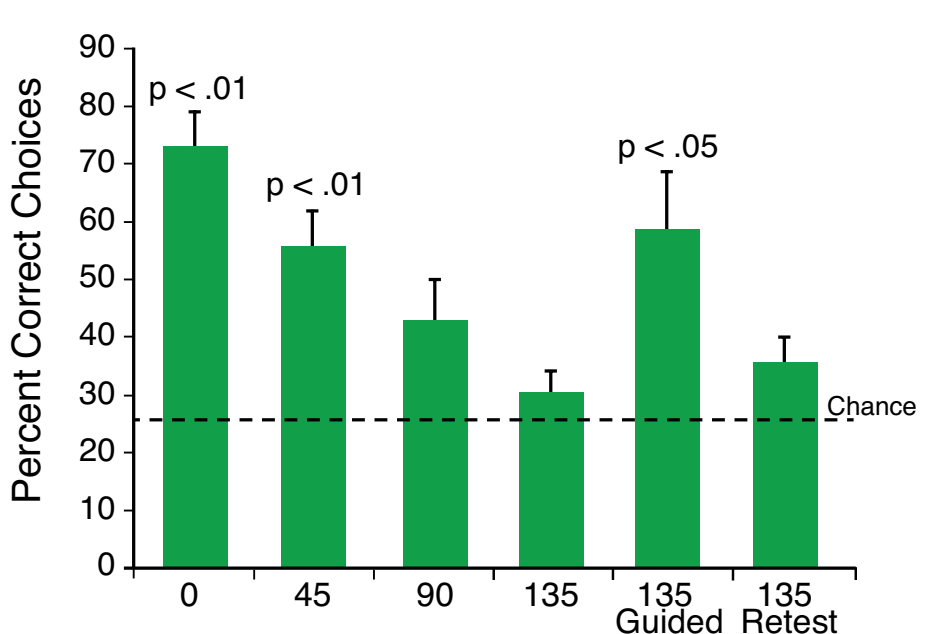

Degree of Box Rotation

Figure 14. The percentage of trials on which dogs chose the correct white box is shown for tests on which the boxe were rotated from $0^{\circ}$ to $135^{\circ}$. Reprinted from "Dogs choose a human informant: Metacognition in canines," by Shannon McMahon, Krista Macpherson, and William A. Roberts 2010, Behavioural Processes, 85, p. 295. Copyright 2010 by Elsevier. Reprinted with perimission.

than chance. No dog moved to reorient itself during these tests. Rather, they continued to approach the boxes from the training position and to push them aside without seeing which one was white. As an attempt to train the dogs to seek information, in the $135^{\circ}$ guided condition, we led dogs by a leash to a position where they could see which box was white and then released them to make a choice. As Figure 14 shows, performance then recovered to significantly better than chance choice of the white box. However, when these dogs then were retested from the training start position with the boxes rotated $135^{\circ}$, their accuracy fell to no better than chance selection of the white box because no dog reoriented to a position where it could see which box was white.

Both Brauer et al. (2004) and McMahon et al. (2010, Experiment 1) failed to find that dogs would voluntarily seek information by moving through space to a position from which information about the correct response could be accessed. These results are reminiscent of the experiment in which rats failed to make a rearing response in order to see a cue that would direct them to the correct alley. However, rats did seek information when they were forced to choose between a response that led to information and one that did not. McMahon et al. carried out further experiments to also force dogs to choose between informative and non-informative stimuli, but the stimuli used had a special character that might favor success with dogs as the subjects. An
outstanding feature of dog behavior is dogs' attentiveness to outstanding feature of dog behavior is dogs' attentiveness to
human cueing in communicative social interactions (Brauer, human cueing in communicative social interactions (Brauer,
Kaminski, Reidel, Call, \& Tomasello, 2006). In two further experiments, dogs could seek information about the location of food from a human informant.

Seven dogs chose between three black boxes placed in a row, with food under only one of them. Before choosing between the boxes on each trial, a dog had to choose to go to one of two people. One person was an informant who subsequently pointed to the correct box. The other person was a non-informant who stood with her back to the dog while it made its choice. The procedure is diagramed in Figure 15
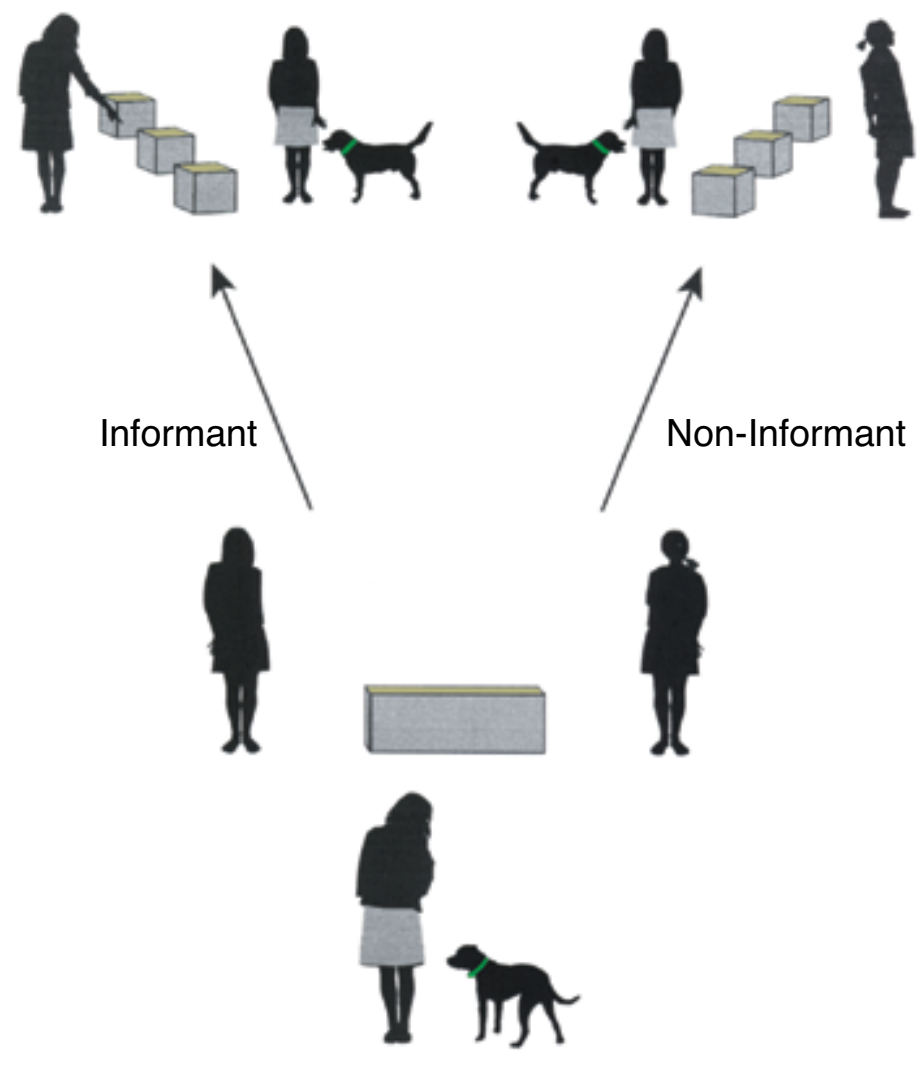

Figure 15. A dog (accompanied by its owner) chooses between two human experimenters, one who acts as an informant by pointing to the correct box among three, and the other who acts as a non-informant by turning her back toward the dog. Reprinted from "Dogs choose a human informant: Metacognition in canines," by Shannon McMahon, Krista Macpherson, and William A. Roberts, 2010, Behavioural Processes, 85, p. 296. Copyright 2010 from Elsevier. Reprinted with permission.

A dog and its owner stood facing two experimenters at the beginning of each trial. When the owner released the dog, it could choose to go to one of the experimenters. If the dog chose the informative experimenter, the owner led the dog o one side of the row of boxes, and the experimenter on the other side of the boxes pointed at the correct box. If the dog chose the non-informative experimenter, the experimente stood with her back to the dog, and the dog had to choose a box with no indication about which box was correct. The roles of informative and non-informative person were bal-

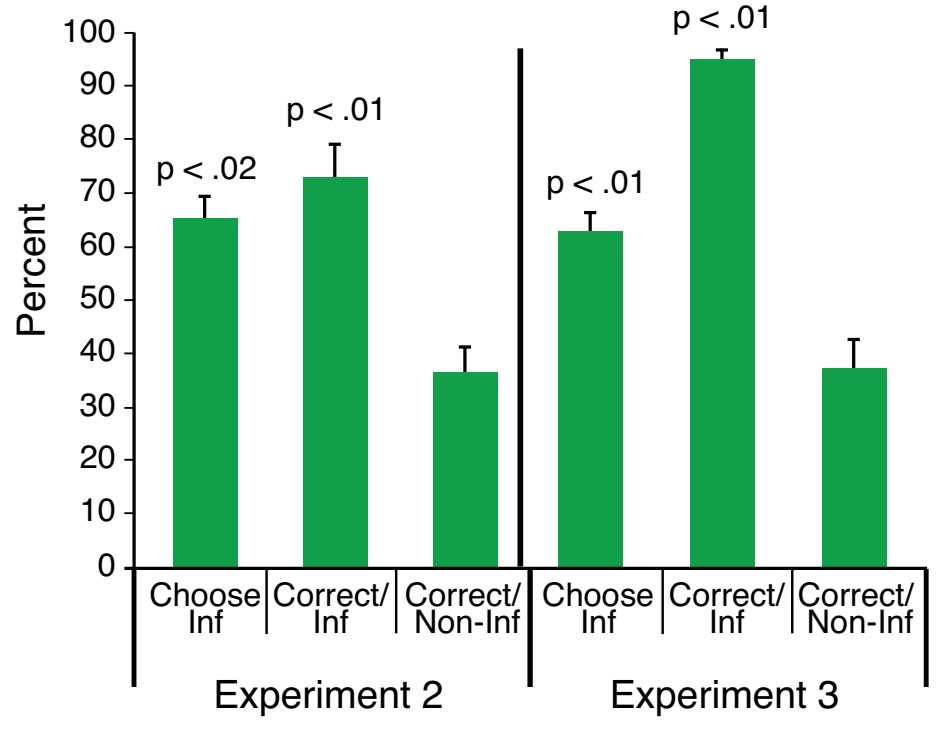

Figure 16. The percentage of choices of the human informant in Experiments 2 and 3. Correct/Inf and Correct/ Non-Inf bars show the percentage of trials on which the correct box was chosen when dogs chose the informant and the non-informant. Reprinted from "Dogs choose human informant: Metacognition in canines," by Shannon McMahon, Krista Macpherson, and William A. Roberts, 2010, Behavioural Processes, 85, p. 297. Copyright 2010 from Elsevier. Reprinted with permission.

anced between the experimenters across dogs, and the leftright positions of the informant and non-informant changed randomly across trials within sessions.

The left panel of Figure 16 shows the results of this experiment for 54 test trials. The Choose Inf. bar shows that dogs chose the informative experimenter on $65 \%$ of the trials and that this percentage significantly exceeded chance $(50 \% ; t(6)=3.35, p<.02)$. The Correct/Inf. and Correct/ Non-Inf. bars show that dogs chose the correct box significantly more often than chance when they had chosen the incantly more often than che whe inno more often than chance (33.3\%) statistically when they chose the non-informative experimenter (36.3\%). The right panel of Figure 16 shows the results of a third experiment carried out with seven new dogs. This experiment was idencarried out with seven new dogs. This experiment was identical to the previous experiment using human informants, but with one change. Now, the rewards received by the dogs on trials when they chose the non-informative experimenter were yoked to those they received when they chose the informative experimenter. Thus, dogs received the same percentage of reinforcements for choosing the informed an non-informed experimenter. The results are very similar to those of the preceding experiment. Dogs chose the informative experimenter on significantly more trials than expected by chance $(62.7 \% ; t(6)=4.07, p<.01)$. They almost always was chosen. When one box was chosen randomly as the "correct" box on trials on which the dog chose the non-informative experimenter, choice of this box did not significantly exceed chance.

The results of the McMahon et al. (2010) experiments are similar to the information seeking rat experiments that we conducted. Although dogs did not discover the re-orienting response necessary to view the correct rotated box in the initial experiment, they did choose the correct cue (person) that provided information about the correct response when they were required to make a forced choice. The level of preference was not high but it was significantly higher than chance in two experiments. Also in line with the rat experiments, dogs chose the informant even when the percentage of reinforcement was equalized for choosing either the informant or the non-informant.

Information Seeking in Honeybees?

Some interesting findings with honeybees should be mentioned in a review of information seeking in animals. Lehre (1993) described the behavior of bees after they had landed at a novel food source:

"I noticed that the bees, upon leaving the reward box after feeding, turn by $180^{\circ}$ to view its entrance, swaying to and fro in front of it, approaching it repeatedly, very much like bees arriving to collect a reward (p. 550)."

Lehrer (1991) labeled this behavior "turn back and look" (TBL) because it appeared that this was exactly what the bees were doing. A series of experiments was performed to examine the functional significance of TBL behavior (Leher, 1993), and the results suggested that bees were using TBL behavior to collect information. The results of severa of Lehrer's experiments are shown in Figure 17. Bees were allowed to repeatedly visit a reward box containing a disc or flower with a drop of sucrose on it. The duration of TBLs upon departure from the rewarded target are plotted over successive departures for different targets and landmarks. The first thing to notice is that TBL duration dropped monotonically over successive departures, suggesting that bees pent less time looking as they acquired more informatio about the reward location.

Figure 17 shows curves for different target conditions, in which the appearance of the target stimulus could be the same or different upon the bee's arrival and departure. In different experiments, the target was a disc that was yellow on arrival and yellow on departure (Disc YEL/YEL), a shape with vertical black and white stripes on arrival and departure (Shape V/V), a disc that was yellow on arrival and blue on departure (Disc YEL/BL), and a shape that was vertical stripes on arrival and horizontal stripes on departure (Shape 


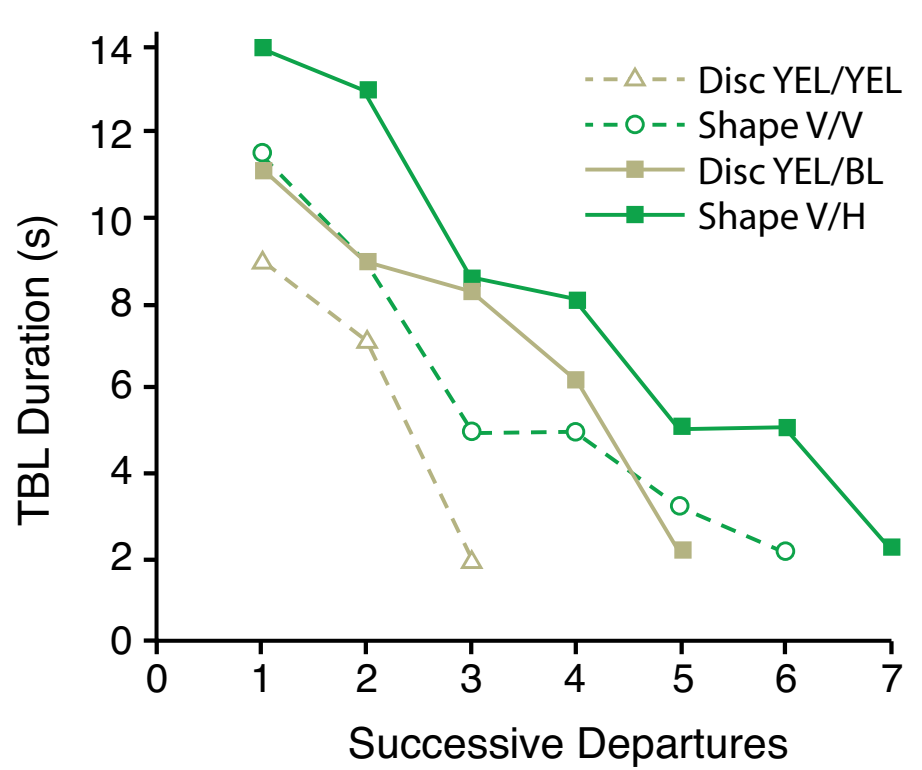

Figure 17. The duration in seconds of TBL behavior shown by honeybees as a function of departures made on successive visits to a food source. Different curves are shown for visual targets seen on arrival/departure. Adapted from "Why do bees turn back and look?" by M. Lehrer, 1993, Journal of Comparative Physiology A., 172, p. 554. Copyright 1993 by Springer-Verlag. Adapted with permission.

$\mathrm{V} / \mathrm{H})$. Notice that the duration of the Disc YEL/YEL curve is lowest, followed by the Shape V/V curve, the Disc YEL/ BL curve, and finally the highest curve is Shape $\mathrm{V} / \mathrm{H}$. These differences can be understood by two factors. First, bee find it easier to discriminate between colors than between black and white patterns. Second, bees need more time to examine the target on departure when the arrival and departure stimuli differ than when they are the same. The ordering of the curves then suggests that bees took more time to examine the target stimuli under conditions that demanded greater acquisition of information.

More recent work by Wei, Rafalko, and Dyer (2002) supports these ideas:

"Our premise is that the degree of investment in the learning flight might correlate with the value the learning fight might correlate with the value of the information that the learning flight would provide. We would therefore expect learning flights to be performed with greater duration whe the bee's uncertainty about the location of foo relative to landmarks is greater, and when the pay-
off provided by the food is greater (p. 726)."

Wei et al.'s (2002) experiments generally confirmed these expectations. It was found that the length of the TBL increased when the complexity of the reward site was increased either by adding additional landmarks or by moving landmarks around from one fight to the next. Food vari- between arrival at the food site and the delivery of food was increased, TBL duration increased. Of particular interest, it was suggested that the TBL duration would be strongly influenced by the value of the information acquired. As the concentration of the sucrose found at the food site increased, bees' TBL duration increased significantly. The suggestion here is that bees choose to acquire more information from sites that have higher payoff

\section{Summary and Conclusions}

Information seeking studies reviewed with non-human primates as subjects suggest metacognition-like processes. These studies have involved apes and monkeys presented with transparent and opaque tubes and containers, with food reward placed in a tube or container. Subjects could often obtain visual access to the location of food by looking through tubes or under containers. In general, apes an rhesus macaque monkeys looked for reward on appropriate occasions; that is, when multiple opaque stimuli were presented and the subject had not seen where food was hidden. Capuchin New World monkeys' performance was not as impressive but still revealed a strong tendency to look down thes.

Because apes and monkeys were not trained to look down ubes or under containers, the observation that they quickly adopted this looking behavior gives it a spontaneous or voluntary quality and suggests some degree of insight into the relationship between looking and gaining information. The findings from our lab with pigeons, rats, and dogs stand in cons dogs, we atcopted dogs, we a tese pre that would reveal information about the location of a hidden ewar. Wis res sions so that they could not see the brightness of a panel that indicated the location of food. This procedure was designe to encourage the rats to rear up and look over the barrier to see the panel. No rat ever made this response. In the case of dogs, after training them to choose the box with a white face for food reward, we gradually rotated the boxes over sessions until the white box could not be seen from the starting position. No dog re-oriented itself by moving to a position where it could see which box was white. Even when dogs were shown how to re-orient by leading them to a position where they could choose the correct box, no dog then reoriented when tested from the original starting position.

Quite different results arose from experiments in which pigeons, rats, and dogs had only two choices between responses, one of which led to information and the other of which did not. In this case, all three species preferred the alternative that led to information. Pigeons preferred to peck a center white key that would provide sample information rather than peck one of two white side keys without information. Rats chose the side of a T-maze that contrin which directed them to the rewarded arm of a secondary alley over the arm that led to non-informative cues. Finally, dogs showed a significant preference for a person that pointed to the correct location of hidden food instead of a person that provided no information about that location.

One aspect of the rat and dog experiments is particularly striking. Rats chose the informative side of the T-maze even though they were rewarded just as often for choosing the non-informative side of the maze. That is, to control for any effects of secondary reinforcement during forced-choice training, rats had been reinforced equally often for tums to the informative and non-informative sides of the turns Similarly in the secol maze. Similarly, in the second dog experiment that involved choice between human experimenters, the probability of reward fo choice of the informative and was the same. Yet, dogs significantly preferred the person that pointed to the box containing food. In both cases, choice of the informative side of the maze or the informative person could not be explained as simply choosing the stimulus that led to more reinforcement

Why should animals prefer informative cues that provide no greater payoff than non-informative cues? One alternative explanation involves a well known phenomenon in the animal learning literature, sign-tracking (Hearst \& Jenkins, 1974). Sign-tracking refers to the fact that animals learn rapidly to approach stimuli which are correlated with or predict the delivery of a reinforcer. Thus, a pigeon learns to peck a key when the onset of the key light is paired with the delivery of food reinforcement, and a rat learns to approach and contact a bar inserted into an operant chamber that has been paired with the delivery of food pellets. The presentation of these events is Pavlovian because the reinforcer is delivered independently of the animal's response, and thus the sign stimulus is often referred to as a conditioned stimulus sign stimulus is often referred to as a conditioned stimulus
(CS) and the reinforcer as an unconditioned stimulus (US). Whe and the reinforcer as an unconditioned stimulus (US) When the CS (Gamzu \&

Williams, 1971, Peterson, Ackil, Frommer, \& Hearst, 1972).

The rats' responses to the brightness cues present in the informative arm of our T-maze were clearly operant in nature because the rats had to make different responses to them in order to obtain reward. From the primary choice point, however, the rat's choice was between informative cues and non-informative cues. These cues were not directly paired with a reinforcer, as in most sign-tracking studies, but they were informative in the sense that they acted as sign-posts that indicated where food was located. Rats may have been drawn to the side of the maze containing informative cues
by a first-order process similar to sign-tracking. Similarly, gs may have been drawn to the person whose behavior was correlated with the location of food. What we sugges is that animals may be programmed through evolutionary hard-wiring to approach or make responses that lead to cues which predict the location of food in space or the delivery of food in time. Notice that this idea of a secondary sign-tracking process could explain some other findings mentioned in his article. In the Zentall and Stagner (2010) study, pigeon preferred to peck a plus sign that led to red and green center key stimuli over pecking a circle that led to yellow and as as samples that were perfectly correlated with the choice of matching comparison stimuli for reinforcement. The yellow and blue cues, on the other hand, were not predictive of reinforced comparison choices. The observing response studies briefly reviewed may also fall into this category Animals preferred to observe stimuli that predicted whether reinforcement would or would not be delivered over cues that were non-informative. Finally, the Gipson et al. (2009) experiment showed that pigeons strongly preferred to peck a key that led to only $50 \%$ reinforcement over a key that led to $75 \%$ reinforcement because the $50 \%$ key led to cues consistently predictive of reinforcement and non-reinforcement and the $75 \%$ key did not.

One implication of this discussion is that it suggests possible comparative differences in the mechanisms responsible for information seeking behavior. A metacognition-like process may be needed to account for information seeking observations made with non-human primates, but a higher order sign-tracking process may be sufficient to account for information seeking results in non-primate animals. We realize that not all theorists will agree with this hypothesis. Some may arge that lower-level associative hypotheses can explain all of the findings with non-human primates. Oth may contend that non-primate species will sow. Others looking responses for information under appropriate testing conditions. We hope that the dichotomous hypothesis of ered here will be propaedeutic for further research on information seeking in animals.

An important area of research may then be to pursue this question with pigeons, rats, dogs, and other non-primates. Could any of these animals be shown to voluntarily adop a novel information seeking response and then use the information to obtain a reward? In experiments that involve a forced-choice method, would animals' preference for a stimulus that leads to information depend on how much information it yielded? As in the Marsh and MacDonald (in press-b) experiments with orangutans, would a non-primate more readily make an observing response for a cue that indicated which of four locations had reward over one that indicated which of three or two locations had reward? Primates 
presumably made the observing response more frequently as the alternatives increased because the probability of reward for a non-informed choice went down as the alternatives increased. We might expect the degree of information to make little difference to an animal that did not understand the importance of information relative to choice alternatives, as long as the cue consistently indicated the location of reward. The number of species examined should be expanded. ward. The number of species examined should be expanded. Species of corvid birds would seem to be a very promising avenue for research on information seeking, given thei success in a number of other areas. In fact, a recent study reported evidence for retrospective metamemory (accurate confidence response following a memory test) in crow (Goto \& Watanabe, in press)

The honeybee findings seem to stand outside this theoretical discussion. For one, many would not have anticipated information seeking behavior in an insect. Second, the TBL behavior described appears to be retrospective in nature. Bees do not seek information to be immediately used to obtain food. Rather, TBL responses appear to gather information about the location of a food site just visited tha will be used to locate that site on a future flight. Although it would be convenient to classify TBL as an invariant speciesspecific response, it is striking that this behavior is flexible and appears to adapt to the need for learned information. Thus, bees perform more extended TBL when difficult to discriminate cues are used, landmarks are sparse or move about, or the quality of food is high. Future research may tell us whether TBL has any continuity with the vertebrate forms of information seeking reviewed here or stands alone as a honeybee adaptation.

\section{References}

Adams, A., \& Santi, A. (2011). Pigeons exhibit higher accuracy for chosen memory tests than for forced memory tests in duration matching-to-sample. Learning \& Behav ior, 39, 1-11. PMid:21264568

Atance, C. M., \& O'Neil, D. K. (2001). Episodic future thinking. Trends in Cognitive Sciences, 5, 533-539. doi.org/10.1016/S1364-6613(00)01804-0

Basile, B. M., Hampton, R. R., Suomi, S. J., \& Murray, E. A. (2009). An assessment of memory awareness in tufted capuchin monkeys (Cebus paella). Animal Cognition, 12 , 169-180. doi.org/10.1007/s10071-008-0180-1

PMid: 18712532 PMCid:2676690

Beran, M. J., \& Smith, J. D. (2011). Information seeking by

Beran, M. J., \& Smith, J.D. (2011). Information seeking by
rhesus monkeys (Macaca mulatta) and capuchin monkeys (Cebus apella). Cognition, 120, 90-105. doi.org/10.1016/j.cognition.2011.02.016

Beran, M. J., Smith, J. D., Coutinho, M. V. C., Couchman, J. J., \& Boomer, J. (2009). The psychological organiza- tion of "uncertainty" responses and "middle" responses: A dissociation in capuchin monkeys (Cebus paella). Journal of Experimental Psychology: Animal Behavior Processes, 35, 371-381. doi.org/10.1037/a0014626

PMid: 19594282

Bower, G., McLean, J., \& Meacham, J. (1966). Value of knowing when reinforcement is due. Journal of Comparative and Physiological Psychology, 62, 184-192. $\underline{\text { dol.org/10.1037/h0023682 }}$ PMid:5969596 tive taking in dogs (Canis familiaris) in the presence of barriers. Applied Behaviour Science, 88, 299-317. doi.org/10.1016/j.applanim.2004.03.004

doi.org/10.1016/j.applanim.2004.03.004

Brauer, J., Kaminski, J., Riedel, J., Call, J., \& Tomasello,
M. (2006). Making inferences about the location of hidden food: Social dog, causal ape. Journal of Comparative Psychology, 120,38-47.

doi.org/10.1037/0735-7036.120.1.38 PMid:16551163 Call, J. (2004). Inferences about the location of food in the great apes (Pan paniscus, Pan troglodytes, Gorilla gorilla, Pongo pygmaeus). Journal of Comparative Psychology, 118, 232-241. doi.org/10.1037/0735-7036.118.2.232 PMid: 15250810

Call, J. (2010). Do apes know that they could be wrong? Animal Cognition, 13, 689-700.

doi.org/10.1007/s10071-010-0317-x PMid.20306102

doi.org/10.1007/s10071-010-0317-x PMid:20306102

.

what they have seen? Animal Cog
doi.org/10.1007/s100710100078

doi.org/ $10.1007 / \mathrm{s} 100710100078$

look. Mind Language, 23, 58-89.

doi.org/10.1111/j.1468-0017.2007.00329.x

Clayton, N. S., \& Dickinson, A. (1998). What, where, an when: Episodic-like memory during cache recovery by crub jays. Nature, 395, 272-274.

doi.org/10.1038/26216 PMid:9751053

Clayton, N. S., \& Dickinson, A. (1999). Scrub jays (Aphelocoma coerulescens) remember the relative time of caching as well as the location and content of their caches. Journal of Comparative Psychology, 113, 403-416.

doi.org/10.1037/0735-7036.113.4.403 PMid:10608564 Couchman, J. J., Coutinho, M. V. C., Beran, M. J., \& Smith, J.D. (2010). Beyond stimulus cues and reinforcent sigJ. D. A new approach to animal metacognition. $J$ out sigComparative Psychology, 124, 356-368.
Solon. Journal of Comparative Psychology,

PMidorg/10.1037/a0020129

PMid:20836592 PMCid:2991470
Crystal, J. D., \& Foote, A. L. (2009). Metacognition in animals. Comparative Cognition \& Behavior Reviews, 4 1-16.

Crystal, J. D., \& Foote, A. L. (2011). Evaluating information-seeking approaches to metacognition. Current Zoology, $57,531-542$.
Csanyi, V. (2000). If dogs could talk: Explaining the canine mind. North Point Press, New York, N. Y.

Dinsmoor, J. A. (1983). Observing and conditioned reinforcement. Behavioral and Brain Sciences, 6, 693728. doi.org $/ 10.1017 / \mathrm{S} 0140525 \mathrm{X} 00017969$

Foote, A. L., \& Crystal, J. D. (2007). Metacognition in the rat. Current Biology, 17, 551-555. doi.org/10.1016/j.cub.2007.01.061 PMid:17346969 PMCid:1861845

Fujita, K. (2009). Metamemory in tufted capuchin monkeys (Cebus paella). Animal Cognition, 12, 575-585. doi.org/10.1007/s10071-009-0217-0 PMid:19242741

Gamzu, E., \& Williams, D. R. (1971). Classical conditioning of a complex skeletal response. Science, 171 923-925. doi.org/10.1126/science.171.3974.923 PMid:5541660

Gipson, C. D., Alessandri, J. J. D., Miller, H. C., \& Zentall, T. R. (2009). Preference for 50\% Reinforcement over $75 \%$ reinforcement by pigeons. Learning \& Behavior, 37, 289-298. doi.org/10.3758/LB.37.4.289 Goto, K., \& Watanabe, S. (in press). Large-billed crows (Corvus macrohynchos) have Retrospective but not prospective metamemory. Animal Cognition.

Hampton, R. R. (2001). Rhesus monkeys know when they remember. Proceedings of The National Academy of Sciences of the United States of America, 98, 5359-5362. doi.org $/ 10.1073 /$ pnas.071600998 PMid:11274360 PMCid:33214

Hampton, R. R. (2009a). Multiple demonstrations of metacognition in nonhumans: Converging evidence or multiple mechanisms? Comparative Cognition \& Behavior Reviews, 4, 17-28.

Hampton, R. R. (2009b). Focusing the uncertainty about nonhuman metacognition. Comparative Cognition \& Behavior Reviews, 4, 56-57.

Hampton, R. R., Zivin, A., \& Murray, E. A. (2004). Rhesus monkeys (Macaca mulatta) discriminate between knowing and not knowing and collect information as needed before acting. Animal Cognition, 7 , 239-246. doi.org/10.1007/s10071-004-0215-1 PMid:15105996

Hare, B., \& Tomasello, M. (2005). Human-like social skills in dogs? Trends in Cognitive Sciences, 9, 439444. doi.org/10.1016/j.tics.2005.07.003 P44. doi.org/10.

Hearst, E., \& Jenkins, H. M. (1974). Sign tracking: The stimulus-reinforcer relation and directed action. Austin, TX: Psychonomic Society.
Hendry, D.P.(1969). Reinforcing value of information: Fixed-ratio schedules. In D. P. Hendry (Ed.), Conditioned reinforcement (pp. 300-341). Homewood, Ill: The Dorsey Press.

Heyes, C. M. (1994). Reflections on self-recognition in primates. Animal Behaviour, 47, 909-919.

doi.org/10.1006/anbe.1994.1123

Heyes, C. M. (1995). Self-recognition in primates: Further relections create a hall of mirrors. Animal Behaviour, 50, 1533-1542.

doi.org/10.1016/0003-3472(95)80009-3

Inman, A., \& Shettleworth, S. J. (1999). Detecting metamemory in nonverbal subjects: A test with pigeons. Journal of Experimental Psychology: Animal Behavior Processes, 25, 389-395.

doi.org/10.1037/0097-7403.25.3.389

Jozefowiez, J., Staddon, J. E. R., \& Cerutti, D. T. (2009). Metacognition in animals: How de we know that they know? Comparative Cognition \& Behavior Reviews, 4, 29-39.

Kelleher, R. T. (1958). Stimulus-producing responses and attention in the chimpanzee. Journal of the Experimental Analysis of Behavior, 1, 87-102. doi.org/10.1901/jeab.1958.1-87

PMCid:1403868

Kendall, S. B. (1965). An observing response analysis of fixed-ratio discrimination. Psychonomic Science, 3, 281-282.

Kendall, S. B. (1974). Preference for intermittent reinforcement. Journal of the Experimental Analysis of Behavior, 21, 463-473.

doi.org/10.1901/jeab.1974.21-463

Mid:16811758 PMCid:1333219

Kornell, N. (2009). Metacognition in humans and animals. Current Directions in Psychological Science, 18,11-15. doi.org/10.1111/j.1467-8721.2009.01597.x Kornell, N., Son, L. K., \& Terrace, H. S. (2007). Transfer of metacognitive skills and hint seeking in monkeys. Psychological Science, 18, 64-71. doi.org/10.1111/j.1467-9280.2007.01850.x PMid: 17362380

Lehrer, M. (1991). Bees which turn back and look. Naturwissenschaften, 78, 274-276.

doi.org/10.1007/BF01134357

Lehrer, M. (1993). Why do bees turn back and look? Journal of Comparative Physiology A, 172, 549-563. doi.org/10.1007/BF00213678 Mackintosh, N. J. (1974). The psychology of animal 
learning. London: Academic Press.

Marsh, H. L., \& MacDonald, S. E. (in press-a). Information seeking by orangutans: A generalized search strategy? Animal Cognition.

Marsh, H. L., \& MacDonald, S. E. (in press-b). Orangutans (Pongo abelii) 'play the odds': Informationseeking strategies in relation to cost, risk, and benefit. Journal of Comparative Psychology.

McMahon, S., Macpherson, K., \& Roberts, W. A (2010). Dogs choose a human informant: Metacognition in canines. Behavioural Processes, 85, 293-298. doi.org/10.1016/j.beproc.2010.07.014 PMid:20708659

Metcalfe, J. (2009). Metacognitive judgments and control of study. Current Directions in Psychological Science, 18, 159-163.

doi.org/10.1111/j.1467-8721.2009.01628.x

PMid:19750138 PMCid:2742428

Middlebrooks, P. G., \& Sommer, M. A. (2011). Metacognition in monkeys during an oculomotor task Journal of Experimental Psychology, 37, 325-337.

Miklosi, A. (2007). Dog behavior, evolution, and cognition. Oxford University Press, Oxford, England doi.org/10.1093/acprof:oso/9780199295852.001.0001

Miklosi, A., Topal, J., \& Csanyi, V. (2004). Comparative social cognition: What can dogs teach us? Animal Behaviour, 67, 995-1004.

http://dx.doi.org/10.1016/j.anbehav.2003.10.008

Nakamura, N., Watanabe, S., Betsuyaku, T., \& Fujita, K. (2011). Do birds (pigeons and bantams) know how confident they are of their perceptual decisions? Animal Cognition, 14, 83-93

doi.org/10.1007/s10071-010-0345-6 PMid:20665063

Nelson, T. O. (1996). Consciousness and metacognition. American Psychologist, 51, 102-116.

doi.org/10.1037/0003-066X.51.2.102

Paukner, A., Anderson, J. R., \& Fujita, K. (2006). Redundant food searches by capuchin monkeys (Cebus apella): A failure of metacognition? Animal Cognition, 9, 110-117.

doi.org/10.1007/s10071-005-0007-2

PMid:16184375

Peterson, G. B., Akil, J., Frommer, G. P., \& Hearst, E. (1972). Conditioned approach and contact behavior toward signals for food or brain-stimulation reinforcement. Science, 177, 1009-1011. doi.org/10.1126/science.177.4053.1009

PMid: 17788815

Povinelli, D. J. (2000). Folk physics for apes: The chimpanzee's theory of how the world Works. Oxford, UK Oxford University Press.

Prokasy, W. F. (1956). The acquisition of observing responses in the absence of differential external reinforcement. Journal of Comparative and Physiological Psychology, 49, 131-134.

doi.org/10.1037/h0046740 PMid:13319523

Roberts, W. A., Feeney, M. C., McMillan, N., MacPherson, K., Musolino, E., \& Petter, M. (2009). Do pigeons (Columba livia) study for a test? Journal of Experimental Psychology: Animal Behavior Processes 35, 129-142. doi.org/10.1037/a0013722 PMid: 19364222

Roper, K. L., \& Zentall, T. R. (1999). Observing behavior in pigeons: The effect of reinforcement probability and response cost using a symmetrical choice procedure. Learning and Motivation, 30, 201-220. doi.org/10.1006/lmot.1999.1030

Shields, W. E., Smith, J. D., \& Washburn, D. A. (1997) Uncertain responses by humans and rhesus monkeys (Macaca mulatta) in a psychophysical same-differen task. Journal of Experimental Psychology: General, 126,147-164. doi.org/10.1037/0096-3445.126.2.147 Shimamura, A. P., \& Squire, L. R. (1986). Memory and metamemory: A study of the feeling-of-knowing phenomenon in amnesic patients. Journal of Experimental Psychology: Learning, Memory, and Cognition, $12,452-460$. 2, 452-460. doi.org/10.1037/0278-7393.12.3.452 PMid:2942629

Shimamura, A. P., \& Squire, L. R. (1988). Long-term memory in amnesia: Cued recall, recognition memory, and confidence ratings. Learning, Memory, and Cognition, 14, 763-770.

doi.org/10.1037/0278-7393.14.4.763 PMid:2972808 Smith, J. D., Beran, M. J., Couchman, J. J., \& Coutinho, M. V. C. (2008). The comparative study of metacog nition: Sharper paradigms, safer inferences. Psycho nomic Bulletin \& Review, 15, 679-691. doi.org/10.3758/PBR.15.4.679

Smith, J. D., Beran, M. J., Couchman, J. J., Coutinho, M. V. C., \& Boomer, J. B. (2009). Animal metacognition: Problems and prospects. Comparative Cognition \& Behavior Reviews, 4, 40-53.

Smith, J. D., Beran, M. J., Redford, J. S., \& Washburn, D. A. (2006). Dissociating uncertainty responses an reinforcement signals in the comparative study of uncertainty monitoring. Journal of Experimental Psychology: General, 135, 282-297.

doi.org/10.1037/0096-3445.135.2.282 PMid:16719654

Smith, J. D., Schull, J., Strote, J., McGee, K., Egnor, R., \& Erb, L. (1995). The uncertain response in the bottlenosed dolphin (Tursiops truncates). Journal of Experimental Psychology: General, 124, 391-408. doi.org/10.1037/0096-3445.124.4.391

Smith, J. D., Shields, W. E., Allendoerfer, K. R., \& Washburn, D. A. (1998). Memory monitoring by animals and humans. Journal of Experimental Psychology: General, 127, 227-250.

doi.org/10.1037/0096-3445.127.3.227

Smith, J. D., Shields, W. E., Schull, J., \& Washburn,

D. A. (1997). The uncertain response in humans and animals. Cognition, 62, 75-97.

doi.org/10.1016/S0010-0277(96)00726-3

Smith, J. D., Shields, W. E., \& Washburn, D. A. (2003). The comparative psychology of uncertainty monitoring and metacognition. Behavioral \& Brain Sciences, 26, 317-373. doi.org/ $/ 10.1017 / \mathrm{S} 0140525 \mathrm{X} 03000086$

Sole, L. M., Shettleworth, S. J. \& Bennett, P. J. (2003) Uncertainty in pigeons. Psychonomic Bulletin \& Review, 10, 738-745. doi.org/10.3758/BF03196540

Son, L. K., \& Metcalfe, J. (2000). Metacognitive and control strategies in study-time allocation. Journal of Experimental Psychology: Learning, Memory, and Cognition, 26, 204-221.

doi.org/10.1037/0278-7393.26.1.204 PMid:10682298

Suda-King, C. (2008). Do orangutans (Pongo pygmaeus) know when they do not remember? Animal Cognition, 11, 21-42. doi.org/10.1007/s10071-007-0082-7 PMid:17437141

Suddendorf, T., \& Corballis, M. C. (2007). The evolution of foresight: What is mental time Travel and is it unique to humans? Behavioral Brain Sciences, 30, 299-313. doi.org/10.1017/S0140525X07001975 PMid:17963565

Sutton, J. E., \& Shettleworth, S. J. (2008). Memory without awareness: Pigeons do not show metamemory in delayed matching to sample. Journal of Experimental Psychology: Animal Behavior Processes, 34, 266-282. doi.org/10.1037/0097-7403.34.2.266 PMid:18426309

Terrace, H. S., \& Metcalfe, J. (2005). The missing link in cognition: Origins of self-reflective consciousness. Oxford, UK: Oxford University Press. errace, H. S., \& Son, L. K. (2009). Comparative metacognition. Neurobiology, 19, 67-74.

Tulving, E. (1972). Episodic and semantic memory. In E. Tulving \& W. Donaldson (Eds.), Organization of memory (pp. 381-403). San Diego: Academic Press. Tulving, E. (1985). How many memory systems are there? American Psychologist, 40, 385-398. doi.org/10.1037/0003-066X.40.4.385

Vila, C., Savolainen, P., Maldonado, J. D., Amorin, I. R., Rice, J. E., Honeycutt, R. L., Crandall, K. A., Lundeberg, J., \& Wayne, R. K., (1997). Multiple and ancient origins of the domestic dog. Science, 276 , 1687-1689. doi.org/10.1126/science. 276.5319 .1687 PMid:9180076

Washburn, D. A., Smith, J. D., \& Shields, W. E. (2006) Rhesus monkeys (Macaca mulatta) immediately generalize the uncertain response. Journal of Experimental Psychology: Animal Behavior Processes, 132 , 185-189. doi.org/10.1037/0097-7403.32.2.185 PMid:16634662

Wei, C. A., Rafalko, S. L., \& Dyer, F. C. (2002). Deciding to learn: Modulation of learning Flights in honeybees, Apis mellifera. Journal of Comparative Physiology A, 188, 725-737.

doi.org/10.1007/s00359-002-0346-2 PMid:12397443 Wycoff, L. B. (1952). The role of observing responses in discrimination learning. Part I. Psychological Review, 59, 431-442. doi.org/10.1037/h0053932 PMid: 13004146

Zentall, T. R. (2011). Maladaptive gambling by pigeons. Behavioural Processes, 87, 50-56.

doi.org/10.1016/j.beproc.2010.12.017 PMid:21215301 Zentall, T. R., Singer, R. A., \& Stagner, J. P. (2008) Episodic-like memory: Pigeons can report location pecked when unexpectedly asked. Behavioural Processes, 79, 93-98.

doi.org/10.1016/j.beproc.2008.05.003

PMid: 18602224

Zentall, T. R., \& Stagner, J. P. (2010). Pigeons prefe conditional stimuli over their absence: A comment on Roberts et al. (2009). Journal of Experimental Psychology: Animal Behavior Processes, 36, 506-509. doi org/10.1037/20020202 